University of Redlands

\title{
Environment and autism analysis
}

A Major Individual Project submitted in partial satisfaction of the requirements for the degree of Master of Science in Geographic Information Systems

by

Jeremy A Woelke

Douglas Flewelling, Ph.D., Committee Chair

Nader Afzalan, Ph.D.

July 2016 
Environment and autism analysis

Copyright ( 2016

by

Jeremy A Woelke 
The report of Jeremy A. Woelke is approved.

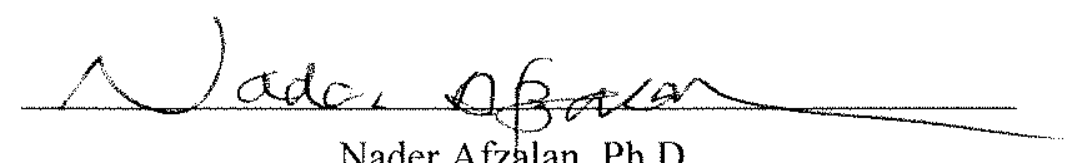

Nader Afzalan, Ph.D.

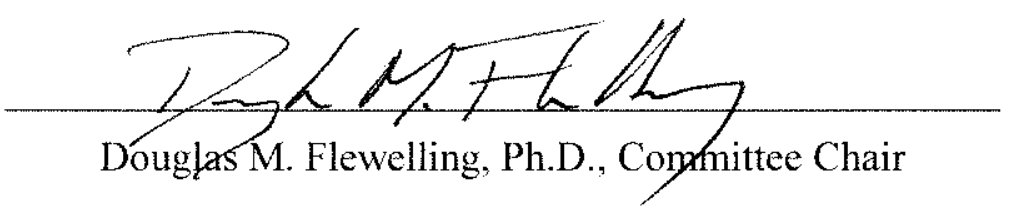

July 2016 




\begin{abstract}
Environment and autism analysis

by

Jeremy A. Woelke
\end{abstract}

The following document looks at the subject of autism from an environmental perspective. Autism is an increasing condition in developed countries and has both genetic and environmental factors involved. This study looks at autism density in the Southern California Unified School District system in conjunction with the presence of both mercury and lead presence. This study found that there was some correlation between high presence of these two substances and high case density in areas of high population. 



\section{Table of Contents}

Chapter 1 - Introduction ................................................................................................ 1

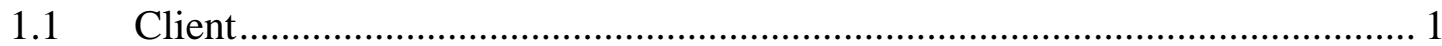

$1.2 \quad$ Problem Statement ........................................................................... 2

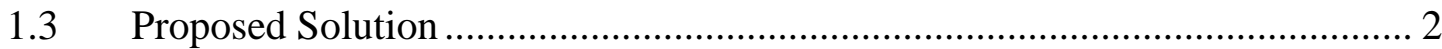

1.3.1 Goals and Objectives ........................................................................... 2

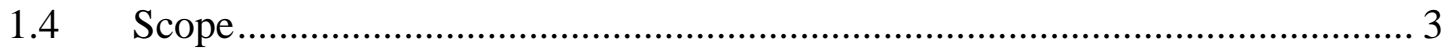

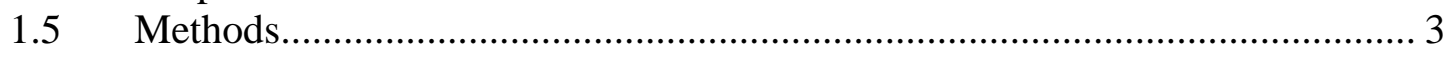

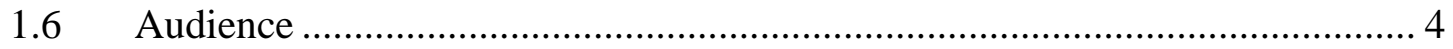

1.7 Overview of the Rest of This Report …………………............................. 4

Chapter 2 - Background and Literature Review ............................................................. 5

$2.1 \quad$ Health, Medicine, and Geography ……………....................................... 5

$2.2 \quad$ Autism Spectrum Disorder …………………………............................... 5

2.3 How does the Environment affect Autism? ................................................. 10

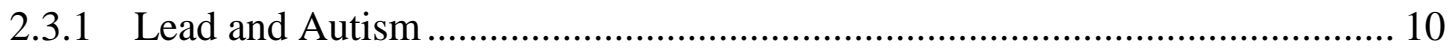

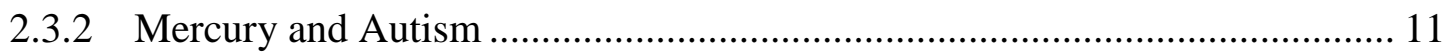

2.3.3 Arsenic, Air Pollution, and Autism.............................................................. 11

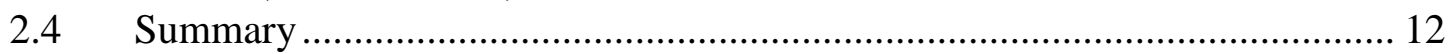

Chapter 3 - Systems Analysis and Design........................................................................ 13

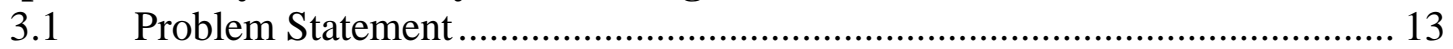

3.2 Requirements Analysis ………………………....................................... 13

3.3 System Design .................................................................................. 13

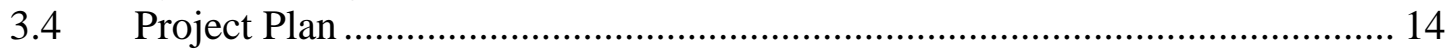

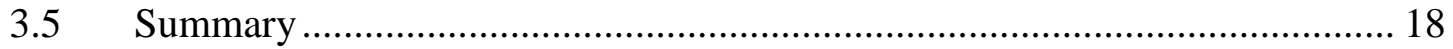

Chapter 4 - Database Design................................................................................................ 19

4.1 Conceptual Data Model ...................................................................... 19

4.2 Logical Data Model ........................................................................... 19

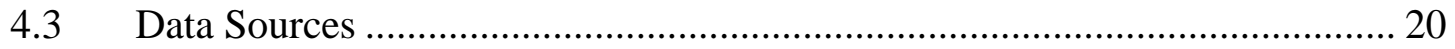

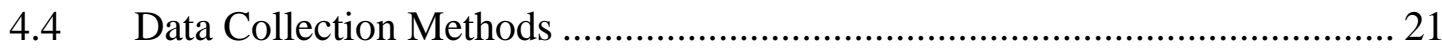

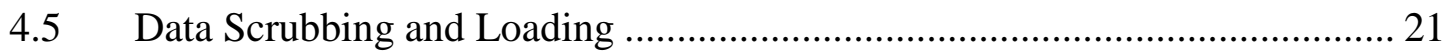

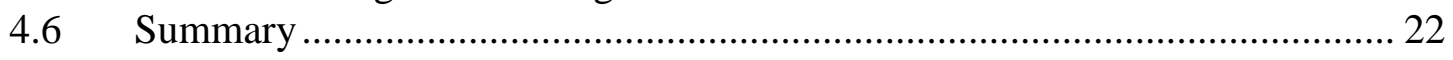

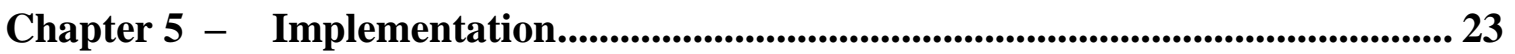

Chapter 6 - Results and Analysis.................................................................................... 30

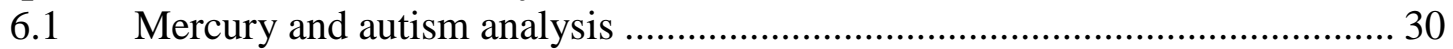

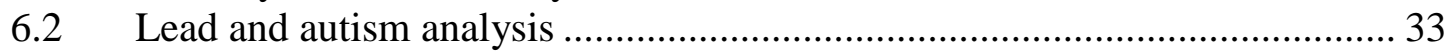

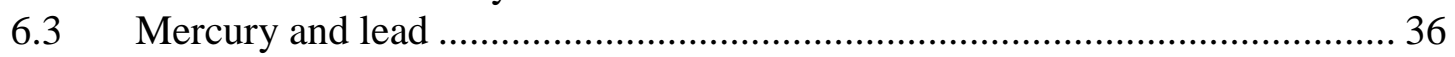

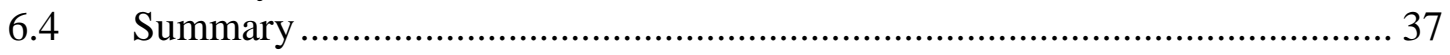

Chapter 7 - Conclusions and Future Work ...................................................................... 39

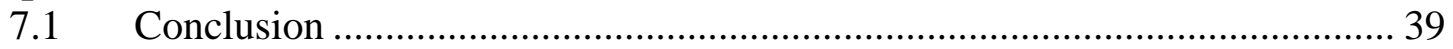

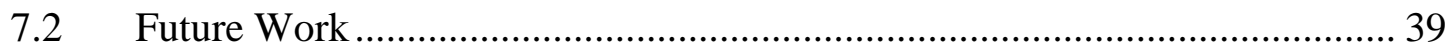

Chapter 8 - Works Cited ...................................................................................... 40 


\section{Table of Figures}

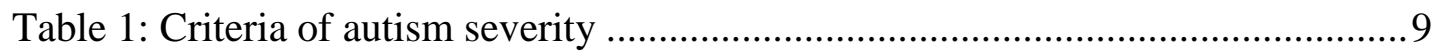

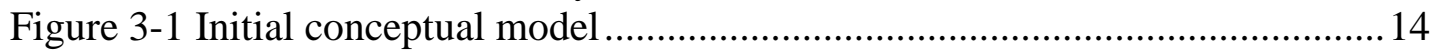

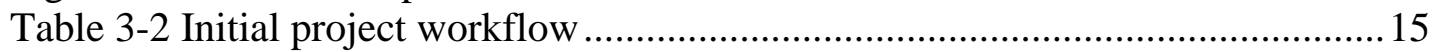

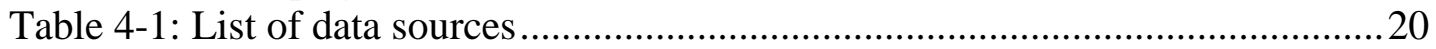

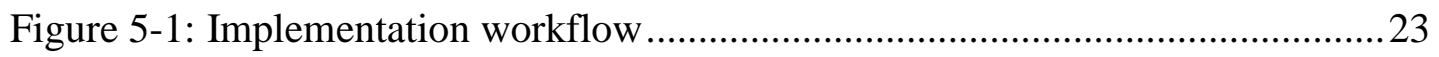

Figure 5-2: Table of contents showing multiple layers of geochemical data ............24

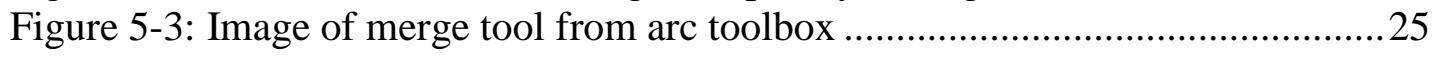

Figure 5-4: Join tool from ArcGIS Desktop ..........................................................26

Figure 5-5: Map appearance after point data was spatially joined and unusable polygons were removed ..........................................................................2 27

Figure 5-6: Compiled autism/environmental map of southern California ................28

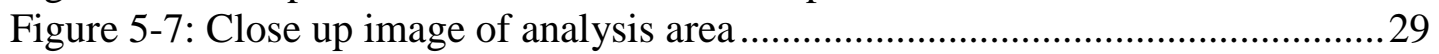

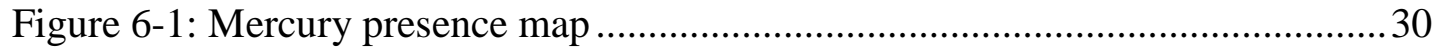

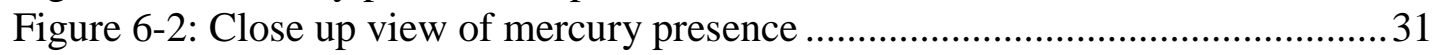

Table 2: Autism/mercury relations in table format ................................................ 32

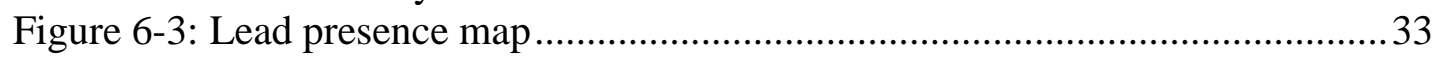

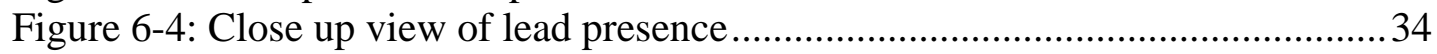

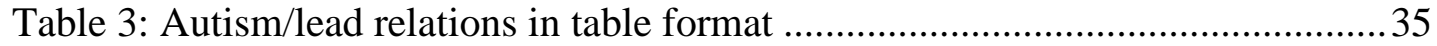

Figure 6-5: Mercury vs lead comparison map .................................................... 36 



\section{List of Tables}

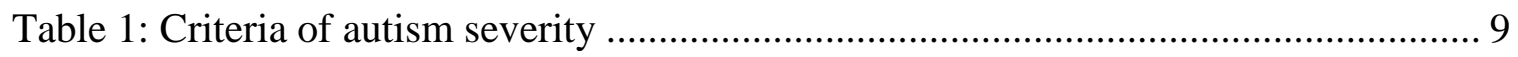

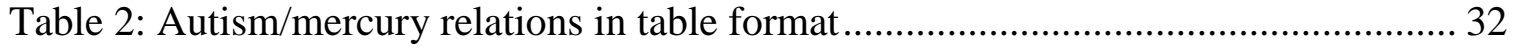

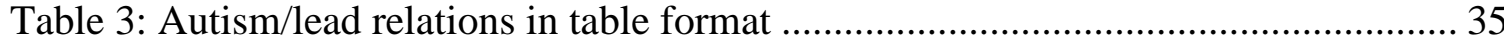





\section{List of Acronyms and Definitions}

ASD Autism Spectrum Disorder

An acronym used to define the umbrella of disorders that make up the various autistic conditions. These conditions range from savant-level disorders with no social capacity to high-functioning conditions that are almost unnoticeable or easily misdiagnosed. 



\section{Chapter 1 - Introduction}

The developed world is evolving at an incredible pace. Every day, new technologies and breakthroughs occur, which change society and our understanding of it. However, with all of this rapid advancement, unexpected issues and problems will arise.

The condition of autism is a broad spectrum of disorders that currently affects one out of eighty-eight children in the United States, with over 35,000 born with it each year accorder to the United States Center for Disease Control and the American Psychiatric Association. And these numbers are increasing. In the year 2000, the case density was 1 within 150 children. (US Department of Heath and Human Services, 2016) Cases are defined by professional psychiatric criteria rated from light too severe with lighter cases being able to function in society than the more severe ones. The most severe cases can be diagnosed as early as age 2 with the highest functioning diagnosable by the age of 6 . (US Department of Heath and Human Services, 2016). What has caused this change? What is known is that there are both environmental and genetic components involved. The list of substances that have been identified as contributors to the development of this condition is long and varied, some of which will be examined more closely below. What is not known is how these contributors interact with each other and how much influence each one has.

Adults with autism, live their lives very differently than what a 'normal' person would. They can see the world in a variety of different ways and have trouble with multiple social interactions and empathizing with others (American Psychiatric Association, 2013). During their lifetimes, many non-autistics look at them and find them to be arrogant, clueless, and unwilling to compromise. Although many were not diagnosed as an autistic individual until much later in their life. In today's society, autistic identification and intervention occurs at a much younger age than it did 20 years ago. Many adults can count themselves fortunate if there were individuals in their lives that were able to support them enough until they could stand on their own. This has often afforded them the ability to have both an education as well as a chance to live.

The opportunity for an education has exposed me to the wonders and possibilities of geospatial technology. Can this technology be used to help both individuals and researchers better understand the questions of how the environment influences the development of autism? That is the purpose of this project.

\subsection{Client}

The primary client for this project was Dr. Susan Porter, Assistant Professor and Chair of the Education Specialist Program at the University of Redlands. She has over sixteen years of expertise working with individuals with various disabilities and specializes in developing coursework for Autistic Spectrum Disorder (ASD). She has also served with the California Commission on Teacher Credentialing. Individuals whom also participated in the study included Beth Burt, head of the Autism Society Inland Empire, a local nonprofit devoted to improving the lives of individuals diagnosed on the Autism Spectrum. 


\subsection{Problem Statement}

There are two main contributors to the autism condition: the well-researched genetic component and the much less understood environmental component. Because environment influences everyone, medical professionals and researchers need more tools in order to investigate these environmental conditions. Current technologies simply do not have the capacity to measure and correlate all of the known environmental contributors. There are many straightforward concerns ranging from air and water pollution, to more subtle factors such as the way food is grown. While much research does exist that tells scientists if something in the environment does affect the condition, (Becerra, Wilhelm, Olsen, Cockburn, \& Ritz, 2013) (Aisha, 2015) (Ihde, et al., 2014) there is much less information that explores the severity of those effects, how widespread the effects are, and how multiple environmental influences work in conjunction with each other. Each condition has the potential to affect Autism in both scale and scope. A method must be determined to isolate each factor and determine its impact on the Autism Spectrum.

\subsection{Proposed Solution}

In the following section, a detailed project plan is demonstrated. This includes the overall goals and objectives of the project, a complete scope of what was involved, and a set of methodologies that were employed to ensure a completed timeline of development, as well as what was completed by each benchmark.

\subsubsection{Goals and Objectives}

To solve these issues of mapping some of these contaminants, a GIS model was designed to compare the outputs of environmental factors and create averages of presence of these substances within these areas as they are related to aggregate case data a school district level. This data model looked at the results of environmental data from two data sources, then created results that show average case numbers within a school district from ages two to twelve. The data needed to be normalized based upon the total school student population, which was taken from the California Department of Education. This will be discussed more in Chapter Three. Ultimately, this model will be able to accept multiple datasets, but the scope of this project was limited to two sets of data. It is important to note that the temporal component of exposure to these substances and the actual confirmation of cases was not included due to circumstances that will be looked at in Chapter 4 . However, in Chapter Seven, the possibility of future expansion of this project will be examined.

This will be invaluable to researchers because it will allow them to visually correlate the presence of known autism contaminants to confirmed autism case data. It is also expected that this GIS can be used as a platform to add additional environmental inputs to acquire an even better understanding of how the environment impacts autism. 


\subsection{Scope}

As previously stated, the ultimate goal for this line of development will be to create a comprehensive data model that can accept multiple sets of data for comparison: one set of autism case data, based at the school district level, and two sets of environment data, known to be autism contributors. This will develop into a comparative data model that. These data will cover the same geographic areas as the school district data.

The project plan for this proposal was completed by the end of May, 2015. And included the development and completion of the model itself using an ArcGIS desktop system. It also involved the cleaning and imputing of both the environmental and autism datasets as well as a calculation to normalize all of the data.

The responsibilities of the developer included:

- Acquiring mercury and particulate pollution environmental data

- Development of all software model components

- Cleaning and preparing the data

- Performing analytics with the data

The client's responsibilities included:

- Providing autism data for model use

- Access to background research material

- Relaying any important updates regarding discoveries in the autism field concerning environment

\subsection{Methods}

The overall methodology design was a waterfall format of development. Stages were clearly laid out with benchmarks. The total time for full project completion was five months.

The first objective was acquiring all of the data necessary for the project. Client involvement was limited to providing the necessary Autism data sets. The task of seeking out environmental data was to begin once the decision on the exact scope of the location data was made. After that, the environmental data was located. This proved to be more challenging because it was unknown what format that data was in and what the size and complexity of the data would be. Various data sets, especially in dealing with the environment are not in any sort of universal standard. That can make finding ways to make these data sets challenging at best.

Second, was the conceptual design of the model. The initial design of the model was based largely on how and what kind of data was to be used. To that end, a rough design of the data model would be necessary before the data could be cleaned.

Stage Three was data scrubbing. This was expected to be the most time consuming part of development. This was due to the unknowns of the amount of data and what specific aspects of the data would be needed.

Stage Four included the actual development and testing of the model. This was also expected to be time consuming but not to the extent that Stage Three was. Here, physical development of the model was completed, as well as initial testing, to make sure that viable and correct results were generated. 
The final stage was finalization and delivery, including report generation, final formatting, and design issues. This was being done as a separate step to ensure that there was ample time to accurately remedy any problems that had arisen in the previous stages.

\subsection{Audience}

The primary audience for this project was Dr. Susan Porter. While she has extensive knowledge of ASD, her knowledge of geographic information systems is much less comprehensive.

This report may also be used by any future graduate students or researchers for advancement of research into the field of autism. This can include hospitals, environmental groups, and various health researchers.

\subsection{Overview of the Rest of This Report}

In the following chapters, the stages of development for this project are explained. All sections are clearly defined and have specific purposes in relations to the project.

Chapter 2 gives a detailed account of background information and literature description of known environmental contributors to autism, some of their specifics, as well as explanations on how they can potentially affect condition under the Autism Spectrum Disorder umbrella.

Chapter 3, includes a full description of scope, as well as the initial timeline of development, and a detailed description of the conceptual model design.

Chapter 4 shows the steps that were taken to gather the data, clean the data to make them useable for analysis, and the design and development of the database. This section also contains the structural database.

Chapter 5 details the implementation of the project. The logical model of how the data were actually entered into the system and specifics about pre-analysis are stated and addressed.

Chapters 6 and 7 describe in detail the analysis and its results as well as explain the conclusions gathered from analysis of the data, as well as potential avenues of exploration that a GIS professional might undertake in the future. 


\section{Chapter 2 - Background and Literature Review}

In the chapter below, applications of geography in both health and medicine have been discussed. Also, a concrete definition of what autism is as it is defined by the medical community has been given as well as an overview how metals such as lead and mercury present in the environment can contribute to the development of the condition. In addition, other substances such as arsenic, particulate matter, and general air pollution are also looked at.

\subsection{Health, Medicine, and Geography}

The concepts of geography and medicine have many intersections and divides and has been labeled as a sub-set of both medicine and geography. (Brown, McLafferty, \& Moon, 2010) It is important to understand that medical geography and health geography are considered separate topics even though both ideas and practices are under the sub-set domain.

Medical geography is considered a misconception in today's understanding of medicine, health, and geography and has come to be understood as the geography of health and disease (Brown, McLafferty, \& Moon, 2010). Today, it is known as epidemiologic geography and includes the mapping of genetic, bacterial, and viral events.

Health geography on the other hand is a sub-discipline of what was once referred to as 'medical geography' and is defined a broad field of various methodologies and ideas and is more theoretical in nature. It focuses on the broader aspects of health and wellbeing as well as broader conceptual models in social aspects (Brown, McLafferty, \& Moon, 2010).

This is an important distinction, but some conditions can blur the lines between what would be considered health geography and what would be epidemiological geography. Autism being a condition that has aspects of both genetic and environmental involvement as well as major social impacts is one such condition (American Psychiatric Association, 2013). Other conditions that can blur this line would include type 1 Diabetes as well as various forms of cancers as they are both considered to have environmental triggers as well as genetic disposition.

\subsection{Autism Spectrum Disorder}

The average person may have a vague sense of what Autism Spectrum Disorder means, but be unaware of what exactly the specifics of the condition are. The American Psychiatric Association defines this disorder in two ways using a series of criteria. Some of the criteria are static in there meaning while others require a severity scale. The criteria are as follows.

"Persistent deficits in social communication and social interaction across multiple contexts, as manifested by the following, currently or by history (examples are illustrative, not exhaustive; see text):

1) Deficits in social-emotional reciprocity, ranging, for example from abnormal social approach and failure of normal back-and-forth 
conversation; to reduced sharing of interests, emotions, or affect; to failure to initiate or respond to social interactions.

2) Deficits in nonverbal communicative behaviors used for social interactions, ranging, for example, from poorly integrated verbal and nonverbal communication; to abnormalities in eye contact and body language or deficits in understanding and use of gestures; to a total lack of facial expressions and nonverbal communication.

3) Deficits in developing, maintaining, and understanding relationships, ranging, for example, from difficulties adjusting behavior to suit various social contexts; to difficulties in sharing imaginative play or making friends; to absence of interest in peers." (American Psychiatric Association, 2013, p. 50)

As stated above, the American Psychiatric Association further defines Autism on a scale of severity. It is for this reason that Autistic conditions cover a wide variety of disorders rather than just a single condition. The severities for social communication impairments are defined as follows.

"Restricted, repetitive patterns of behavior, interests, or activities, as manifested by at least two of the following, currently or by history (examples are illustrative, not exhaustive; see text):

1) Stereotyped or repetitive motor movements, use of objects, or speech (e.g., simple motor stereotypies, lining up toys or flipping objects, echolalia, idiosyncratic phrases).

2) Insistence on sameness, inflexible adherence to routines, or ritualized patterns of verbal or nonverbal behavior (e.g., extreme distress at small changes, difficulties with translations, rigid thinking patterns, greeting rituals, need to take same route or eat same food every day).

3) Highly restricted, fixated interests that are abnormal in intensity or focus (e.g., strong attachment to or preoccupation with unusual objects, excessively circumscribed or perseverative interests).

4) Hyper- or hypo-reactive to sensory input or unusual interest in sensory aspects of the environment (e.g., apparent indifference to pain/temperature, adverse response to specific sounds or textures, excessive smelling or touching of objects, visual fascination with lights or movement). (American Psychiatric Association, 2013, p. 50)

The above criteria are not specific to ASD. In fact, a number of other psychological conditions could potentially fall into this category depending on who the evaluator is as well as the individual patient. For this reason, Autism Spectrum Disorder is considered to be an 'umbrella' term that is used to classify a broad range of similar conditions.

In addition to the above criteria, three more variables are used to identify Autism Spectrum Disorder. They are as follows:

1) "Symptoms must be present in the early developmental period (but may not become fully manifest until social demands exceed limited capacities, or may be masked by learned strategies later in life).

2) Symptoms cause clinically significant impairment in social, occupational, or other important areas of current functioning. 
3) These disturbances are not better explained by intellectual disability (intellectual developmental disorder) or global developmental delay. Intellectual disability and autism spectrum disorder frequently co-occur; to make comorbid diagnoses of autism spectrum disorder and intellectual disability, social communication should be below that expected for general developmental level." (American Psychiatric Association, 2013, pp. 50, 51)

To work in conjunction with the above criteria, as special three tier scale was developed to judge severity. The table on the following page, also provided by the American Psychiatric Association provides the scale that doctors use to gauge the severity of individuals with autism. (American Psychiatric Association, 2013, p. 52) 



\begin{tabular}{|c|c|c|}
\hline Severity level & Social communication & Restricted, repetitive behaviors \\
\hline $\begin{array}{l}\text { Level } 3 \\
\text { "Requiring very substantial support }\end{array}$ & $\begin{array}{l}\text { Severe deficits in verbal and nonverbal communication skills } \\
\text { cause severe impairments in functioning, very limited initial of } \\
\text { social interactions, and minimal response to social overtures from } \\
\text { others. For example, a person with few words of intelligible } \\
\text { speech who rarely initiates interaction and, when he or she does, } \\
\text { makes unusual approaches to meet needs only and responds to } \\
\text { only very direct social approaches. }\end{array}$ & $\begin{array}{l}\text { Inflexibility of behavior, extreme difficulty coping } \\
\text { with change, or other restricted/repetitive behaviors } \\
\text { markedly interferes with functioning in all spheres. } \\
\text { Great distress/difficulty changing focus or action. }\end{array}$ \\
\hline $\begin{array}{l}\text { Level } 2 \\
\text { "Requiring substantial support" }\end{array}$ & $\begin{array}{l}\text { Marked deficits in verbal and nonverbal social communication } \\
\text { skills; social impairments apparent even with supports in place; } \\
\text { limited initiation of social interactions; and reduced or abnormal } \\
\text { responses to social overtures from others. For example, a person } \\
\text { who speaks simple sentences, whose interaction is limited to } \\
\text { narrow special interests, and who has markedly odd nonverbal } \\
\text { communication. }\end{array}$ & $\begin{array}{l}\text { Inflexibility of behavior, difficulty coping with } \\
\text { change, or other restricted/repetitive behaviors appear } \\
\text { frequently enough to be obvious to the casual } \\
\text { observer and interfere with functioning in a variety of } \\
\text { contexts. Distress and / or difficulty changing focus or } \\
\text { action. }\end{array}$ \\
\hline $\begin{array}{l}\text { Level } 1 \\
\text { "Requiring support" }\end{array}$ & $\begin{array}{l}\text { Without support in place, deficits in social communication cause } \\
\text { noticeable impairments. Difficulty initiating social interactions, } \\
\text { and clear examples of atypical or unsuccessful responses to social } \\
\text { overtures of others. May appear to have decreased interest in } \\
\text { social interactions. For example, a person who is able to speak in } \\
\text { full sentences and engages in communication but whose to-and- } \\
\text { fro conversation with others fails, and whose attempts to make } \\
\text { friends are odd and typically unsuccessful. }\end{array}$ & $\begin{array}{l}\text { Inflexibility of behavior causes significant } \\
\text { interference with functioning in one or more contexts. } \\
\text { Difficulty switching between activities. Problems of } \\
\text { organization and planning hamper independence. }\end{array}$ \\
\hline
\end{tabular}

Table 1: Criteria of autism severity 
All of the above criteria are used to define what (ASD) is. These include patterns of behavior as well as social communication. Both from barely noticeable patterns to the most extreme cases. (American Psychiatric Association, 2013). Patterns of behavior could include drawing specific types of things, using the same words to describe different things, and even following the same routes of travel regardless of circumstances.

Now why is it important to define the above criteria in this paper? Psychological conditions can often be confused with one another due to a great many having similar displayable symptoms. For example, autistic conditions can often be misdiagnosed as Rett syndrome, Attention Deficit Disorder, or any number of basic intellectual disabilities (American Psychiatric Association, 2013). It is for this reason that specific criteria have been presented to ensure that the reader fully understands what it means to have an autistic condition.

Currently, both the United States Centers for Disease Control and Prevention (2015) as well as the American Psychiatric Association (2016) agree that at the present date and time, approximately $1 \%$ of the total human population is afflicted with some variation of Autism Spectrum Disorder.

\subsection{How does the Environment affect Autism?}

Now that a thorough explanation of what autism is has been presented, the next step is to examine just how some environmental factors affect the condition. Below, three different environmental items will be looked at lead, mercury, and particulate matter. While each of these items and their effects on the human body have been extensively looked at for various conditions, only data pertaining to autism and relevant studies will be discussed.

\subsubsection{Lead and Autism}

Lead is a heavy element that was at one point used in many industrial and commercial applications. It was later learned that lead was toxic to the human body and was cause for a number of medical conditions. One of which was autism. Results of a number of studies have shown that toxic metals and substances have an effect on prenatal development (Aisha, 2015), (Adams, et al., 2009), (Ihde, et al., 2014). A study conducted in New Jersey shows that heavy concentrations of lead do impact autistic development (Ihde, et al., 2014). This study also shows that points of toxic contamination are linked to cases of autism are frequent. Ihde et al also suggests that in urban areas, where concentrations of these materials are more common, rates and cases of autism also increase. In fact, the same study shows that within the study area, over 86,000 points of lead toxicity can be linked to increases of autistic cases along the map where the points are most dense (Ihde, et al., 2014).

An additional study shows that air releases of lead and other substances with a release rate of at least $100 \mathrm{lb}$ within a $39.12 \mathrm{~km}$ median centroid distance shows to may have caused increases in autism between the years 1991 to 1999 (Aisha, 2015). While in of itself, the increase is not dramatic, data continues to suggest that lead-based contamination does in fact have an impact on autism case density and severity. Particularly, white males are most at risk (Aisha, 2015). This is important as this study does find that white males had the highest ASD density of all racial groups observed. 
A third study published in the Journal of Toxicology also corroborates that lead contamination does have correlation between exposure and possibility of autism development and shows high correlation between lead and autism (Adams, et al., 2009).

\subsubsection{Mercury and Autism}

In addition to lead, mercury another heavy metal and the only liquid metal element has also been shown to be a contributing factor to autism. Mercury has been used well over one hundred years in a variety of industrial applications. And because of its liquid nature, its contamination is extensive and can exist as well as move though the environment quite easily (Geier, King, \& Geier, 2008). Mercury can easily exist in animal tissue and, until the turn of the century, many prescription and over the counter medications contained mercurial variations as well also point out that unlike other heavy metals, mercury does not break down but persists in the brain even after exposure, even in low levels. Studies have also pointed out that there has been significant correlation between the introduction of $\mathrm{Hg}$ and increases in ASD (Geier, King, \& Geier, 2008),. In addition, studies have also found that mercury contamination and ASDs can affect development both pre-natal as well as post-natal and even early development (Adams, et al., 2009), (Aisha, 2015), (Adams, et al., 2009), (Ihde, et al., 2014). A discovery by Geier, was that studies show that mercury contamination does not need to be as high in content as other elements such as lead to have an adverse effect on neurological development. This is due to an individual's biological tolerance to mercury.

\subsubsection{Arsenic, Air Pollution, and Autism}

A third element that has shown to be a developmental cause for autism is Arsenic. Like lead, arsenic is a byproduct of industrial development (Aisha, 2015). However, unlike elements such as mercury, arsenic is primarily an air dispersed contaminant (Aisha, 2015). "Both long-term and short-term exposures to ambient air pollutants have been shown to stimulate oxidative stress and inflammation in humans, which may also affect neurologic development" (Aisha, 2015, p. 246). Studies also suggest that ambient air pollution containing heavy metals may also contribute to the development of autism (Becerra, Wilhelm, Olsen, Cockburn, \& Ritz, 2013). Research conducted by Idhe et al shows the high concentrations of arsenic can also impact autism development. Arsenic contamination was only behind lead in terms of presence within their study area

Another compressive study of air pollution and particulate matter conducted in California has shown that residences that were located near areas of high particulate matter that had children in the gestation phase as well as the first year of life were at a higher risk of developing autistic conditions (Volk, Lurmann, Penfold, Hertz-Picciotto, \& McMonnell, 2013). The study also found that nitrogen dioxide exposure while pregnant as well as during the first year of life can also impact autism development.

Air contaminants are not just limited to simple elements and particulate matter. Studies examining exposure to various complex airborne chemicals have also been conducted. One such study has found that there is correlation between exposure to organochlorine pesticides during pregnancy can also contribute to ASD development (Roberts, et al., 2007). 
A third study conducted in California has also found evidence that proximity to freeways during gestation and pregnancy can also impact the development of Autism (Volk, Hertz-Picciotto, Delwiche, Lurmann, \& McConnel, 2011). The study does suggest that a link exists between autism and the US population that resides within $100 \mathrm{~m}$ of major highways (Volk, Hertz-Picciotto, Delwiche, Lurmann, \& McConnel, 2011) This information suggests that arsenic exposure in air pollutants as well as particulate matter and other airborne contaminants play a role in the increase in autism prevalence.

\subsection{Summary}

In this chapter, the clinical definition of autism was examined. Diagnosis of this condition is far more complex given the criteria than one would expect. This is part of the reason that autism is considered an 'umbrella' of conditions rather than a single allencompassing neurological condition.

Also in this chapter, various known contributors of autism were looked at. Specifically lead contamination, mercury exposure, and arsenic pollution were detailed. A number of studies were also cited as to show that these and many other elements have been examined in an attempt to explain how the environment impacts severity and prevalence of autism. While the genetic side of the condition continues to be a primary focus of research, this information has shown that additional and much more comprehensive study of the environment and how it influences autism development is needed to fully understand how both sides of the autism equation balance out. 


\section{Chapter 3 - Systems Analysis and Design}

In this chapter, the system analysis and assessment of risks and other aspects of the project is detailed. This includes the initial timeline for development, aspects of quality control, identified potential risks, and other information native to this section.

\subsection{Problem Statement}

The problem addressed in this document was showing how a selection of environmental contributors, in this case mercury and lead, have the potential to affect the possibility of acquiring Autism Spectrum Disorders as well as the potential severity.

The client desired a method to analyze patterns of autism density at as small a scale as possible while comparing that with concentrations of known environmental contributors. To that end, a comprehensive collection of autism case data at as small a scale was necessary as well as aligning environmental data. What follows was the initial project plan. This included the requirements for the system, initial timeline for development, potential problems anticipated, and initial aspects of quality control.

\subsection{Requirements Analysis}

There were many requirements necessary to both complete the analysis and draw logical conclusions from the collected data. The first meeting with the client was extensive and illuminating. The client made clear that how an extensive analysis tool to analyze all of the known environmental contributors of autism was missing. What the client had asked for was a tool that could serve as a foundation for such an extensive analysis system. Initial requirements would include a geodatabase that would hold the data and an automatic tool system that could perform analysis on the data held within. This held a number of smaller requirements. Some of these included the acquisition of useable data, developing a universal format for the data, the normalization, and formatting of the information as well as potential risks involved, comprehensive quality control over certain data that spanned years, and development of a database design that could be easily altered in accordance with various spatial and temporal data. Also expected at the conceptual design phase as a set of python-inspired tools that could automatically be run on the data, a map set that would be generated, as well as a physical report that would be created for all persons involved.

\subsection{System Design}

The system presented to the client consisted of a single geodatabase design. Within this database, the content was split into a pair of featuresets; one for environmental data and the other for relevant autism education data. This environmental data in this model has been narrowed down to lead and mercury contamination. The data was then further broken down into individual datasets centered on a particular subject matter. This way, the data could be manipulated independently of the other either in the event that the location for analysis was changed or the type of educational data to be analyzed needed to be corrected or changed out. Initial conceptual layout looked like the following: 


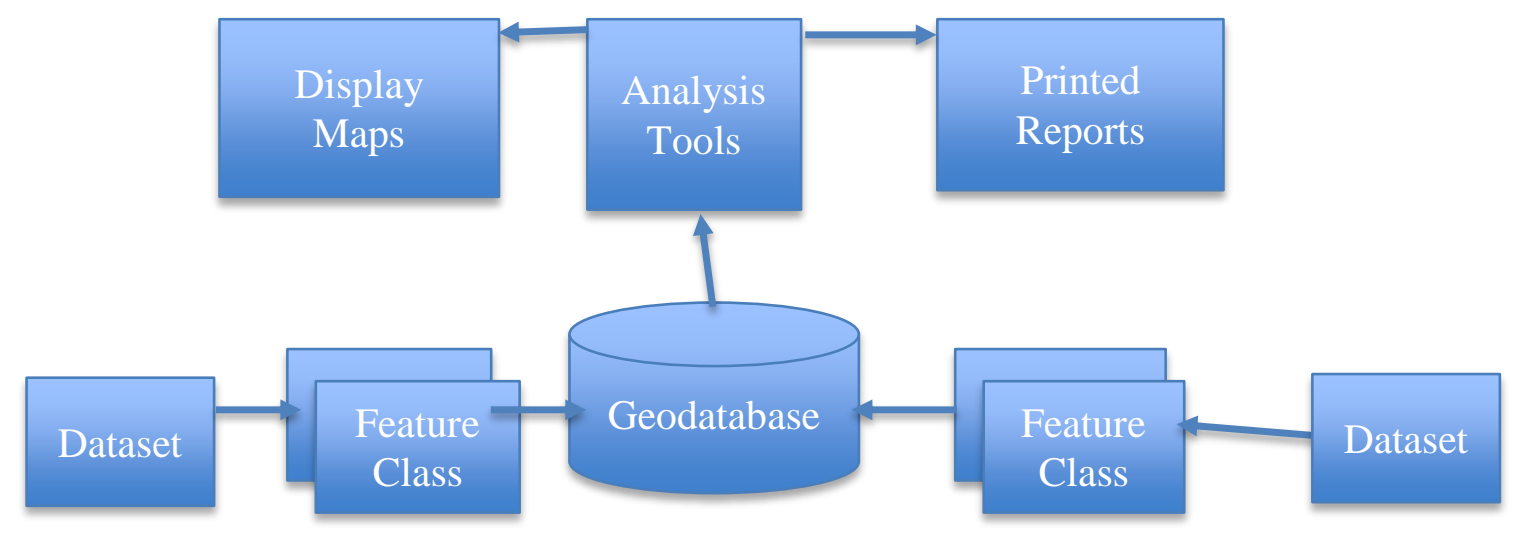

\section{Figure 3-1 Initial conceptual model}

In the above diagram, everything is centered around a file geodatabase. Connected to that geodatabase are two feature classes each which have one or more feature datasets attached to them. At this stage of development, the addition of feature classes was not actually necessary since a very select number of datasets were being used. However, the feature classes were added in the event that there was future expansion of this project and may be required. All of which would feed into the analysis tool and display system located above the geodatabse.

Within the environmental feature set, all of the environmental data was included. This also meant that anything related to the environment was present as well. All of the highway data, as well as the environmental point data were located here.

The education featureset included the various created tables that were made based on the California Department of Education's collection of special needs data. In this case, their 2014-15 special need autism data for ages one through 12 were used. Also within this featureset included all of the normalized tables as well as the raw data, and any spatially joined data that was used for analysis.

\subsection{Project Plan}

The initial project plan called for a five-month project in which time, the data was to be gathered and cleaned, the analysis performed, the report written and presented, and the entire project defended.

The stated project started on January $1^{\text {st }}$ of 2015 with initial design. The project was developed, tested, and deployed with final delivery completed by Mid-May of 2015. Initial concept development and data collection had begun before finalization of the initial timeline. The workflow below gives a brief description of each phase followed by a more detailed breakdown of each phase and what tasks were slated to be completed within each phase (any times mentioned were adjusted in the event of unforeseen issues) 
Phase 1 - Structural Development

Phase 2 - Database and Analysis Development
- 1.1 Collection of Data

- 1.2 Initial Geodatabase Design

- 2.1 Cleaning of Data based on initial Geodatabase Design

- 2.2 Load Autism Data

- 2.3 Matching of Environmental Data based on Autism Data
Phase 3 - Structural Refinement and Testing

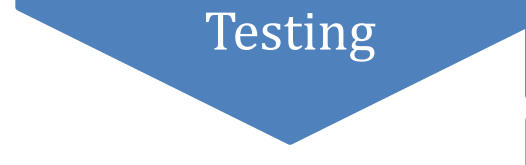

Phase 4 - Complete Refined Project

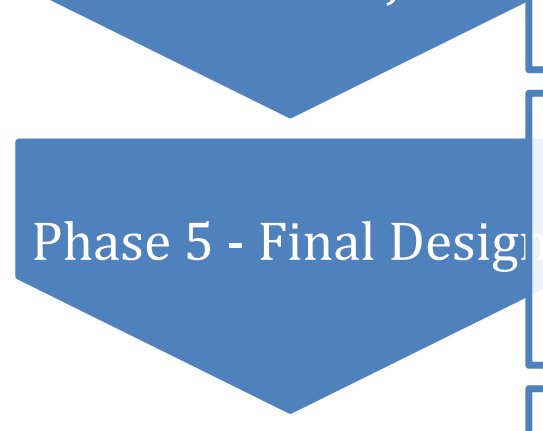

Phase 6 - Project Delivery
- 3.1 Refine Geodatabase based on Analysis Tool Design

- 3.2 Correct any issues with Analysis of Data

- 4.1 Finalize elements for presentation

- 4.2 Present elemts to Client for inspection

- 5.1 Refine all tools and geodatabase for final delivery

- 5.2 Final product testing

- 5.3 Conception and development of perhiperal materials

Table 3-2 Initial project workflow 


\section{Phase 1. January - Structural Development:}

During this month, the initial geodatabase design had begun with what data had already been collected. At that point, the data was not cleaned and only basic structure was completed. Final data collection was completed. This included all environmental data. Milestone task for this phase was the development of a working geodatabase with the data that works with the raw data.

Several third tier phases were conducted during this period to allow for completion of the phase. These included the collection of the autism data, which was retrieved from the California Department of Education(CDE) web site. The collection of the environmental data which was gathered from several sources. These included both data on lead and mercury as well as a number of other potential data sources.

Conceptual development of the geodatabase was also begun at this point. Items that were completed at this point were various. Domains and sub-types were determined. At this point, no solid commitments to either were made. The number of featuresets and feature classes were looked at. At this phase of development, a single-database, with two feature classes was deemed to be most appropriate and the system of how to load the data was examined.

The client was also provided with a roadmap so that progress could better be gauged. This included how the geodatabase was to be best designed, how the data was to be loaded, and what the plan for the system of analysis would be.

\section{Phase 2. February - Database and Analysis Development:}

During this phase, all data was stripped and cleaned to the necessary components. Geodatabase was to be refined to match the cleansed data. Data loading was to be completed during this phase. In addition, initial development of analysis tools was to also be performed. It was expected that development of the analysis tools was time intensive as model building and python scripting were to be required. Milestone for this phase was to the completion of a working analysis tool that worked with the data-loaded geodatabase.

There were also a complex number of sub-phases with this section of the project as well. The first included the scrubbing of the data. The autism data turned out to be much more complex to work with. The client presented a scenario where the autism data could be downloaded and used in a table format which would be easy to import and use. Upon further investigation, this turned out not to be the case. The data that the client was referring to was intended for viewing only and was not available in a downloadable format. In order to acquire the autism data in a useable format, the data had to be copied directly from the California Department of Education's web site into a Microsoft Excel workbook. The environmental data was fairly straightforward. Almost all that had to be completed was removing all of the unnecessary data. The environmental data went through several versions with each one having more and more of the unusable data removed until it became acceptable to use. After the data had been cleaned and examined, it was also determined that no synthetic data would need to be added as previously expected. The next step in making the autism data useable was to apply normalization to 
it. These calculations were performed in Excel but will be explained in greater detail in chapter 4.

Now that all the data was in useable formats, the time came to construct the geodatabase. As expected, only a single geodatabase was necessary. From that, two feature datasets were created. One for the autism data, and one for the environmental data. Also as expected, no domains or sub-types for the geodatabase were necessary. Due to the issues with the aggregation of the data, analysis tools were becoming less and less likely.

At this point, the data could now be uploaded into the geodatabase. This was done with by converting the workbooks into coma-delaminated text and converted into featureclasses using ArcCatalog with each type of data being stored within its own featureset. Data was also tested in ArcMap and both the environmental data and the autism data were loaded without issue.

Final sub-phase looked into the development of an analysis toolset to create automated analysis. After looking into the application, it was determined that this was not feasible due to the fact that other datasets would not be in a universal enough format to create any kind of automated processes within the time-frame of this project. As such, the toolset was abandoned in favor of a straightforward analysis. The client was informed of this change and accepted the changes to the project. Analysis and visual display of the results was moved to phase 5 .

\section{Phase 3. March - Structural Refinement and Testing:}

At this stage of project development, Refinement of the geodatabase and the data was to be conducted based on the workings of the analysis tools. At that time it was unknown how exactly those tools will work so it was important to incorporate time for that at this stage. At that time, finalization of the data was to be conducted. It was at this point, synthetic data were to be added if it was deemed necessary for project finalization. However, now that it had been determined that analysis tools would no longer be used, it was replaced with a format for analysis.

The first step in this phase was to perform a series of comparison tests between the first generation tools and the refined geodatabase noting any bugs or issues that need to be later resolved. The next objective was to ensure that the results of the tools were correct and accurate. This would have included the addition or modification of the tools to ensure accuracy and precision. This would entail the development of $2^{\text {nd }}$ generation toolset for analysis. Final part of this phase would include testing of the refined tools with the current geodatabase and data. This included any flaws within the system as well as the analysis process.

\section{Phase 4. April - Final Design:}

At this phase of development, any outstanding issues were to be addressed for future presentation. This included either form or functions that needed to be corrected, improved, or adjusted. Also at this phase, conceptual design for any additional materials, instructions, or items was performed. This was in anticipation for difficulties the client might have in understanding or using the GIS. Project milestone for this phase was completion of the final deliverable geodatabase and analysis system. 
Within this phase, presentation issues were addressed and the analysis process were fine tuned. This phase was included to ensure that the project met the client's expectations. Next, all elements of the project were presented to the client to ensure that outstanding issues were addressed and the client agreed that the project met their expectations.

\section{Phase 5. May - Delivery Preparation:}

This was the next to final stage of the project. During this time, any materials such as instructions or documentation were completed. This included proper licensing information or metadata needs. Project milestone was delivery of the final project to the client as well as instructional information and metadata.

Here, any final issues that the client had were addressed. This only included smaller issues due to how far the project had come. Final project testing was also completed at this time. After this, no additional testing was performed. Also at this phase any peripheral documentation or metadata was planned for and all relevant information was gathered.

\section{Phase 6. June - Final Delivery}

Phase 6 was the final stage of the project. Here, all the peripheral information was completed and the final project was delivered to the client. Outside of the completion of necessary documentation and metadata, no other steps had to be completed. After that information was gathered, project was presented to the client.

Overall plan implementation had a number of disruptions including the ability to obtain the autism data and the decision to forgo the development of an automated analysis system in favor of a manual analysis. The client was not opposed to these changes. As a buy-in, the client understood that significant changes may be necessary in order to complete the project. However, the client was behind the concept of using GIS technology in order to further understand environmental impacts on autistic development.

Unfortunately, the project plan suffered a number of delays and changes which caused this initial time line to be rewritten. The actual issues that were encountered will be discussed in chapter 4 , but suffice to say, the initial project plan was aggressive in what it both entailed and ultimately was to accomplish.

\subsection{Summary}

In this chapter, the initial project plan was overviewed. It included the restatement of the project problem including what the client initially expected. An analysis of the initial requirements of the project. The system design at the start of the project was also looked at. The initial project plan was also outlined which included the starter timeline from the collection of data to the delivery of the consumables. 


\section{Chapter 4 - Database Design}

Within the following chapter, the systems used to create the database will be detailed. This will include both the conceptual and logical models of the database itself. Also included are details about the data themselves. Where the data was obtained, the methods used for collection, and the systems implemented for both the scrubbing of the data as well as its loading is described.

\subsection{Conceptual Data Model}

Initial model of the systems that were intended for the client involved the development of a database system that could hold and analyze two different types of data. One was school district, the other were environmental in nature. The environmental data was then further subdivided into individual types of data. The database would then be connected to a set of analysis tools that would be used to run analysis on the various types of data.

The database structure was set up this way in order to allow the swapping out of properly formatted data, both on the environmental side of the database as well as on the educational side. This was especially important for the environmental data. Initial concept design would allow for the addition of more data to enable more comprehensive analysis. This was due to the fact that Autism Spectrum Disorders cover a wide range of neurological conditions and many variables both environmental and medical factor in. Most of which is beyond the limited scope of this project. This will be discussed more in depth in chapter 7: Future work. The conceptual design model did not vary much from its initial inception as diagramed in Chapter 3.

\subsection{Logical Data Model}

Once development of the database system had begun, it became clear that a single database structure would be necessary to hold all the data. This was due in part to the limited geographic area that was intended to be used for the system. A file geodatabase was used for this purpose. However, not long into database development, that the construction of a toolset to perform automatic analysis was not going to be possible within the scope of this project. It was at this point that the idea for automatic analysis tools was scrapped and the implementation of a straight up analysis was decided. Data also could not be provided in a unified format to allow for automatic analysis as well. Also educational data could not be aggregated to the school level due to privacy laws. This forced analysis at the district level which reduced the ability to provide high levels of accuracy in relations to the point-based environmental data.

Two feature datasets were then constructed for the geodatabase. One for educational data and the other for environmental. This was done to allow separate control for the different types of data since both types of data were in separate formats. This was also done to allow for the analysis of more than one area at a time for comparison purposes.

Then the data was converted an entered into the datasets. The educational data was provided in a dataset format however, none of the autism data was part of that information. That dataset had to be exported into Microsoft Excel where the data was then added and normalization occurred. Then the data was reconverted back into a 
dataset. Additional datasets were also included within this feature class. These included county line data as well as major highway data though the highway data became beyond the scope of analysis.

The environmental data had a separate set of issues. First much of the initial data collected was not within the target analysis area. This led to the removal of that data and the inclusion of USGS geochemical data for analysis. The target analysis area, in this case Southern California included over a thousand points and was broken up into a number of smaller datasets. These then had to be unified into a single dataset. This will be discussed in chapter 5: Implementation.

In addition to the number of points, the geochemical data set had over forty different molecular compounds within it and many of the points did not have data for every single type of compound. From that, one type of mercury and one type of lead that had the most useable data were selected and the rest of the unnecessary data was removed. This was done while the data was still in tabular format to make it easier to work with in ArcGIS.

\subsection{Data Sources}

Data was collected from accredited web sources as well as from already created datasets. The locations were as follows:

\begin{tabular}{|c|c|}
\hline $\begin{array}{l}\text { California } \\
\text { Department of } \\
\text { Education } \\
\text { Dataquest system: }\end{array}$ & http://dq.cde.ca.gov/dataquest/ \\
\hline $\begin{array}{l}\text { California school } \\
\text { district statistical } \\
\text { data }\end{array}$ & $\begin{array}{c}\text { http://univredlands.maps.arcgis.com/home/item.htm/?id=ded0e763 } \\
\text { c43f46d0b0ff4227e5ef4b3f }\end{array}$ \\
\hline $\begin{array}{l}\text { California } \\
\text { Environmental Data } \\
\text { Exchange Network: }\end{array}$ & http://ceden.org/ \\
\hline $\begin{array}{l}\text { USGS geochemical } \\
\text { survey. }\end{array}$ & http://mrdata.usgs.gov/geochem/ \\
\hline $\begin{array}{l}\text { Full USGS } \\
\text { geodatabase } \\
\text { metadata } \\
\text { documentation }\end{array}$ & http://mrdata.usgs.gov/geochem/doc/home.htm \\
\hline $\begin{array}{l}\text { United States } \\
\text { Department of } \\
\text { Transportation Arc } \\
\text { GIS dataset: }\end{array}$ & $\begin{array}{c}\text { http://univredlands.maps.arcgis.com/home/item.htm/?id=ded0e763 } \\
\text { c43f46d0b0ff4227e5ef4b3f }\end{array}$ \\
\hline
\end{tabular}

Table 4-1: List of data sources 


\subsection{Data Collection Methods}

All data was collected from various sources online. Either from well-known government institutions or from privately maintained data sources. All of the datasets used were downloaded from sites online.

\subsection{Data Scrubbing and Loading}

Data scrubbing and loading proved to be quite challenging especial where the education data was concerned.

The first main issue encountered was that the California Department of Education data was not in either the format or the scope that the client stated that it was in. The education data was in a pure web format and not in any kind of downloadable or normalized form. After an extended period of effort, no way was found to acquire it in any kind of downloadable means. This meant the data had to be entered in by hand, imported into a GIS dataset, and normalized within the GIS platform itself. This caused considerable delay in the project due to initial improper data entry as well as the introduction of unnecessary errors. As such, no metadata was available for this dataset and had to be created by the project head. In addition, the autism data was added to the base education data by exporting the content into Microsoft excel, creating new fields, adding the data, and then importing that table back into the ArcGIS platform as a new dataset. The following formula was used to normalize the lead and mercury data:

\section{(total minimum - individual minimum) / (total maximum - individual maximum)}

The environmental data, while less time consuming to work with was no less problematic. Initially, data from the California Environmental Data Exchange Network would be sufficient for analysis. This was not the case.

Upon further inspection of the datasets, they had sporadic collection points, large amounts of inconsistencies as well as various gaps in collection times. In addition, the data was not of a unified format either in data fields or in locations gathered. Even the times collected was problematic due to the fact that single datasets spanned a decade's worth of collections. Eventually those datasets had to be removed from the analysis.

The USGS data proved to be much more comprehensive than the previous used environmental data. It was easily downloaded from the USGS. However, the entire state's point data could not be downloaded directly as a single file. This led to the downloading of several smaller files and then compiling those datasets into a single large set for analysis. In the end, the geochemical dataset was found to be the most comprehensive and was used as the environmental data provider.

After that dataset was created, it proved to have far too much unusable data. Most of the non-relevant data was then removed. This included unnecessary fields as well as most of the unusable environmental attributes. Only the carbon, mercury, and lead data was retained. 


\subsection{Summary}

In the above sections, the conceptual model as well as the logical model were explained. Scope of project had to be reduced to fit data available as well as unexpected time constraints. Where the data was obtained was also explained. ArcGIS Online as well as various other government and private institutions were vital in providing viable data for analysis. All data was collected from web-based sources. This made both the cleaning of the data simple, if not time-consuming. Also, this made the loading of the data into a featureset geodatabse simple as extensive formatting was not required. 


\section{Chapter 5 - Implementation}

Now that all of the data had been collected, cleaned, and normalized, analysis was now possible. As a straightforward correlation analysis between two sets of information, the process of implementation was simple. The flow of analysis was conducted using the following process:

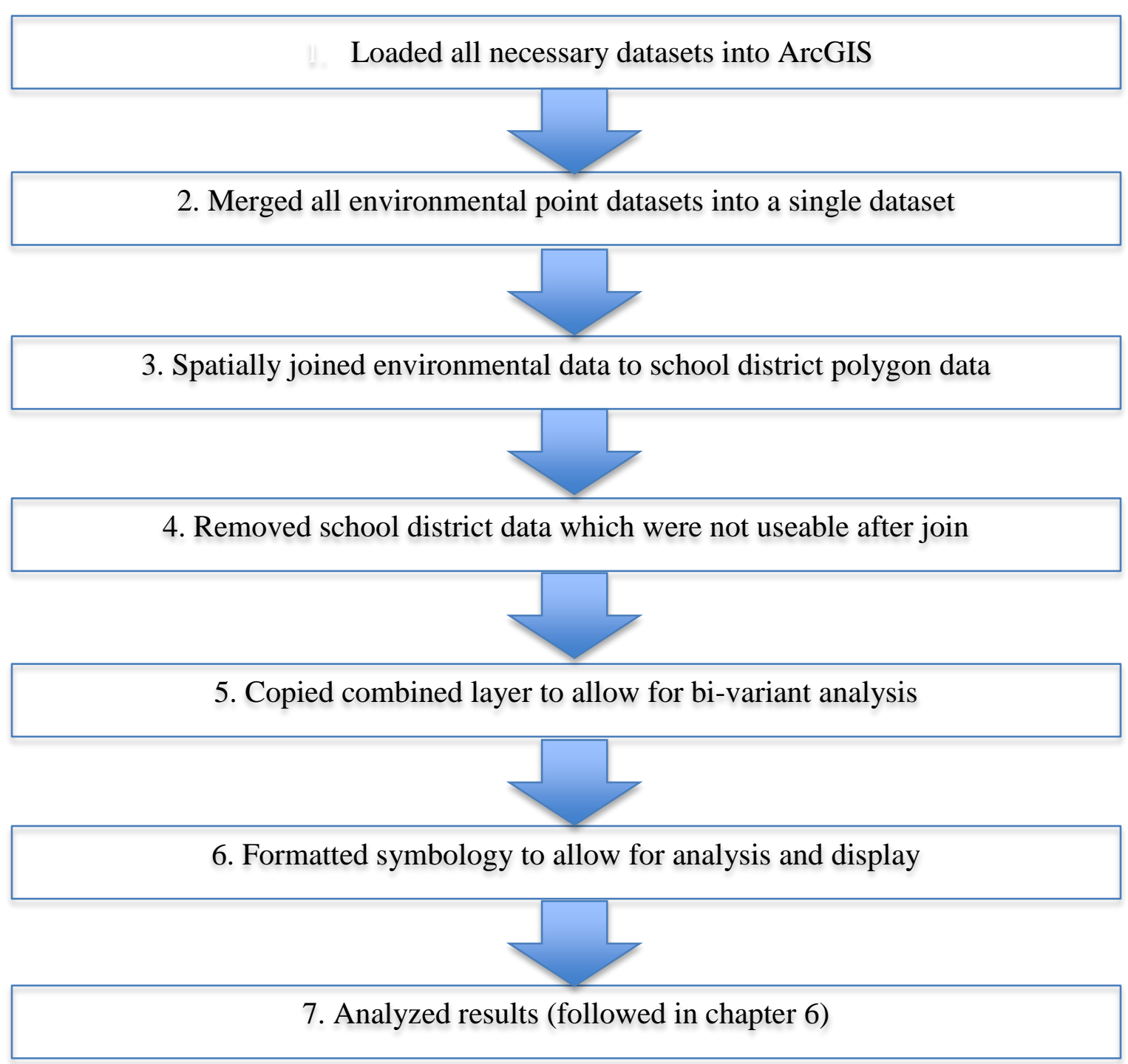

Figure 5-1: Implementation workflow

Arcuis. I nis inciuded tne unined scnoos aistrict aataset, a county ine aataset, and tne environmental dataset that consisted of several smaller datasets from the USGS geochemical survey. However, the USGS data had been broken up into a number of smaller datasets for the purpose of data management. This meant that several datasets 
were necessary in order to cover the entire area of analysis. This caused number of issues including extra points, and points which were outside of the analysis area.

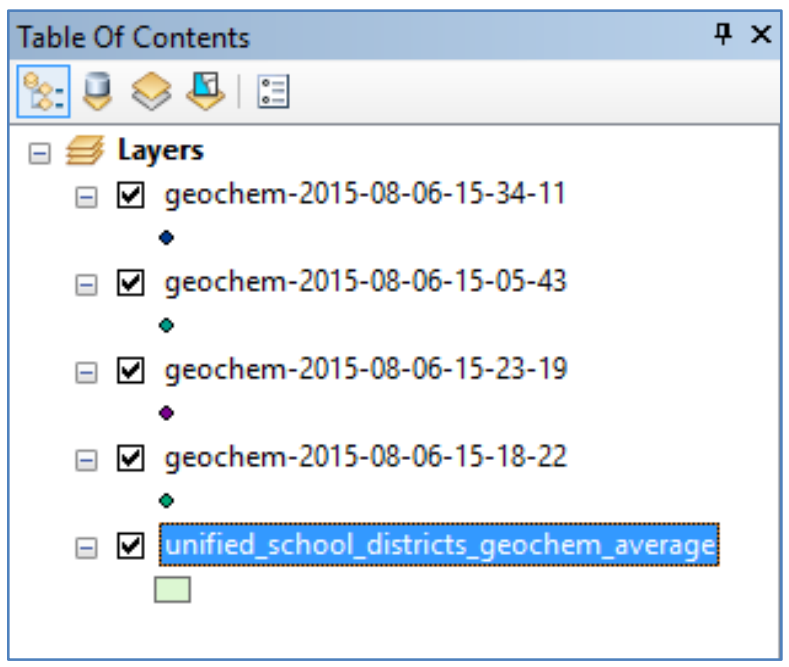

Figure 5-2: Table of contents showing multiple layers of geochemical data

Working with the geochemical data in this form with well over 2 thousand points proved to be unwieldy. A merge process needed to be conducted in order to unify the dataset as well as to remove identical points. 
For the next stage of implementation, a merge geoprocess was conducted on the multiple geochemical datasets to compile them into a single dataset. The merge tool can be found in the data management section of the arc toolbox and looks like this.

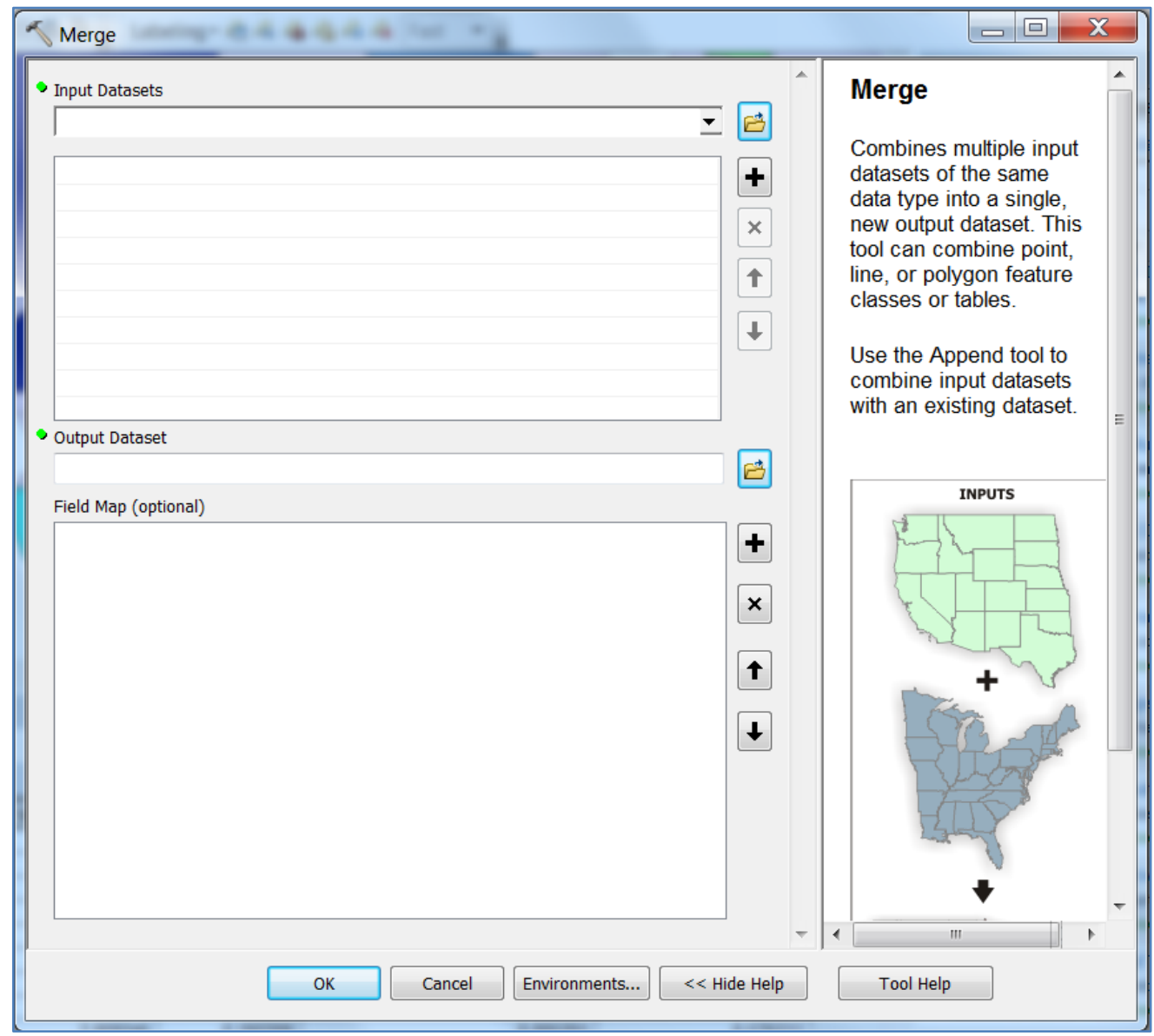

Figure 5-3: Image of merge tool from arc toolbox

Merge is a straightforward tool that allows for the combination of multiple datasets into a single dataset. Useful for both point and polygon data, merge allows for the simplification of multiple datasets into fewer, more manageable ones. In this case, merge was used to combine several point datasets from the USGS geochemical survey into a single dataset.

Third stage of implementation involved the use of the join function of ArcGIS to combine the spatial point data with the school district polygon data. In addition to combining these two datasets into one, the spatial join also allowed for the tabulation of other statistics such as the sum of all the data, the minimum and maximum, the average as well as the standard deviation and variance as well. While most of that information was not used in this analysis, it was included in the event that it was necessary for further analysis. The spatial join function is pictured below. 


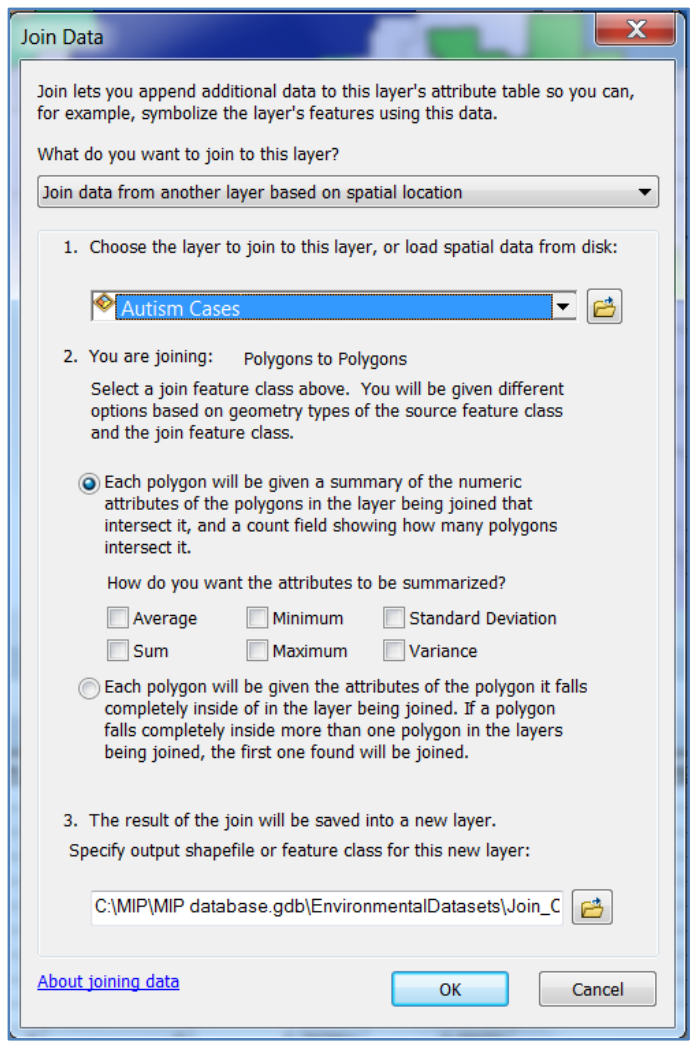

\section{Figure 5-4: Join tool from ArcGIS Desktop}

As can be seen from this image, various data could be joined in this fashion. For purposes of this project, points to polygons was used and a summarization of various types of information was added to the polygon layer rather than the raw dataset data.

Fourth stage of implementation involved the use of a definition query to remove elements from analysis that did not have pertinent information. The following definition query was used to help with this:

$$
\text { Norm_Total_Cases >0 AND (Norm_avg_Hg > =0 OR Avg_pb_icp40 > =0) }
$$

This formula allowed for only the inclusion of polygons that had a Normalized total case population greater than 0 and either a mercury or a lead contamination greater than 0 as well. It is important to note at this point that all lead and mercury concentrations are 
measured in parts per million (ppm). This gives us a map that looks like this:

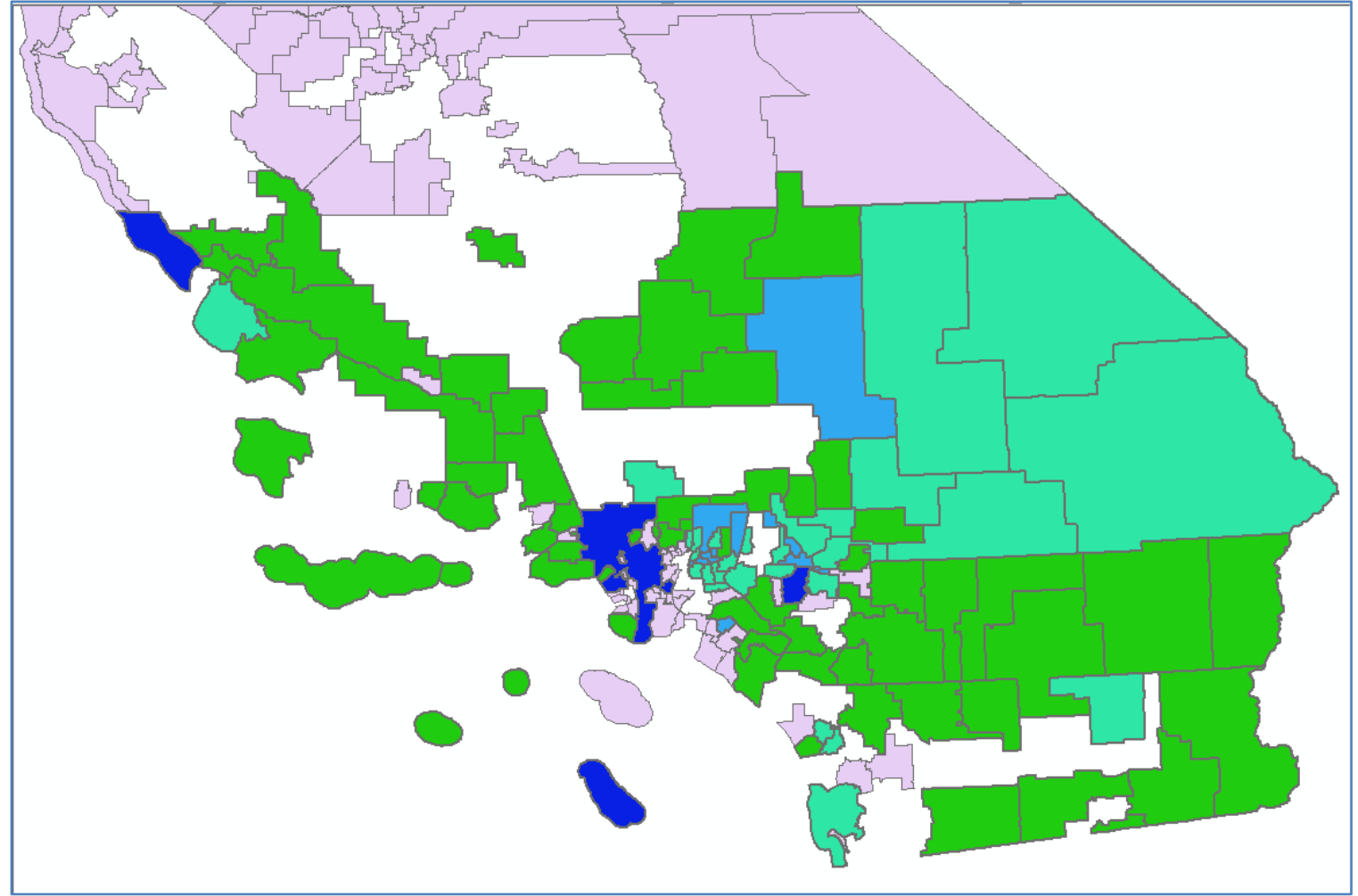

Figure 5-5: Map appearance after point data was spatially joined and unusable polygons were removed

In this image, any polygon that has a total case number $>0$ as stated above as well as either a mercury or a lead content amount $>0$ as well. Any polygon that was lavender in color had no environmental case data to work with. A graduated color ram was used to show environmental concentration. From green to blue representing low to high.

The next step involved in implementation, now that all of the analyzable data was within a single layer, all that was required was that that the layer be copied with the dataset copy function embedded in the right-click menu and to repasted that layer multiple times into the dataframe. This would allow for correlation.

For the next phase, the symbology on the copied layers was altered to show case data in a graduated symbol format as well as a different color ramp for the second 
environmental contaminant. This would allow for a visible understanding of correlation.

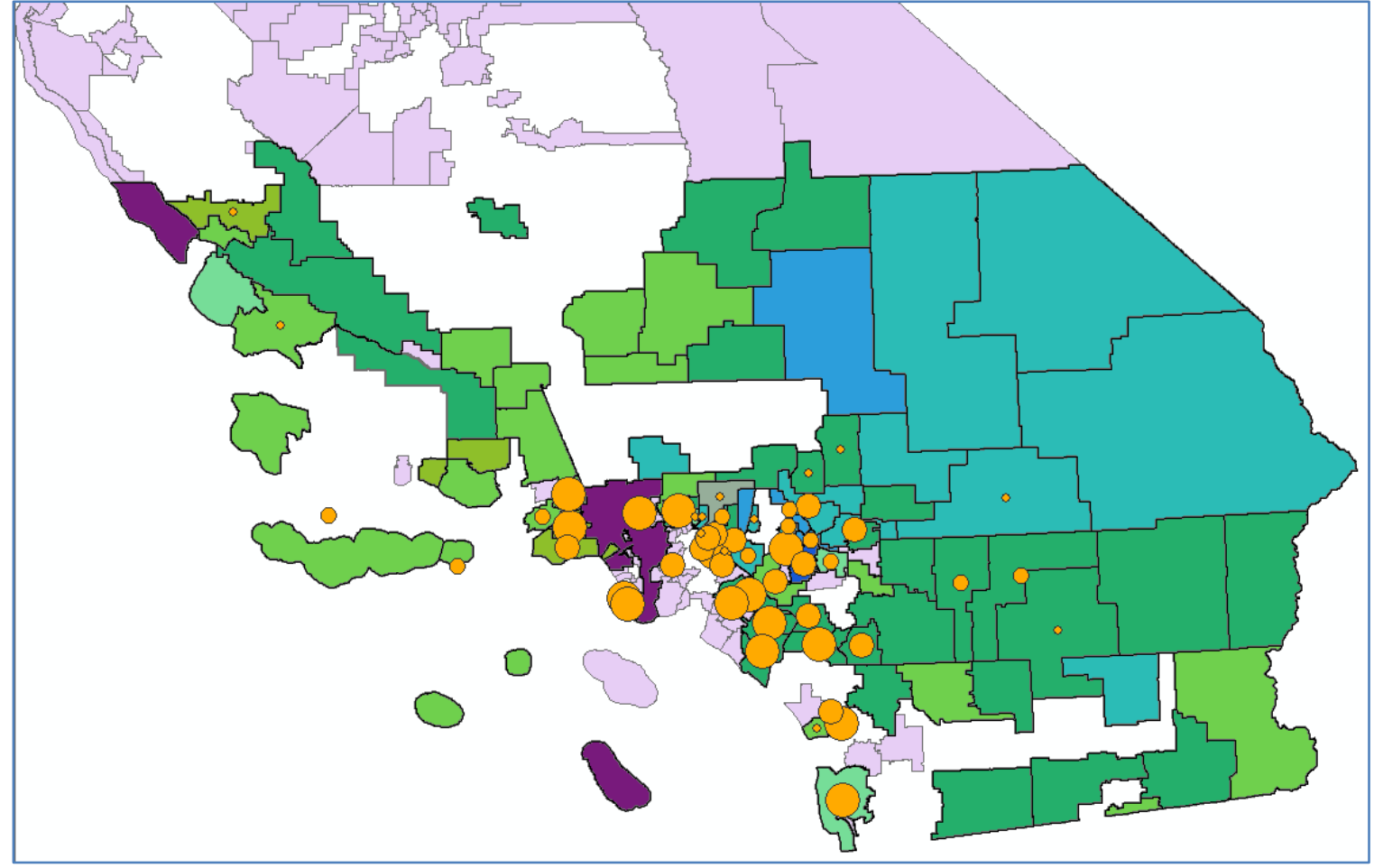

Figure 5-6: Compiled autism/environmental map of southern California 
From this map, a visual correlation between autism cases and mercury/lead contamination can be examined. Any polygon that is shaded but without a corresponding point showing cases is representative of a school district that has reported cases being present, but did not report a quantifiable number. They are included to show that cases are still present but could not be analyzed within the scope of this analysis. The map below shows a zoomed in look where you can see a more in-depth look at the smaller districts.

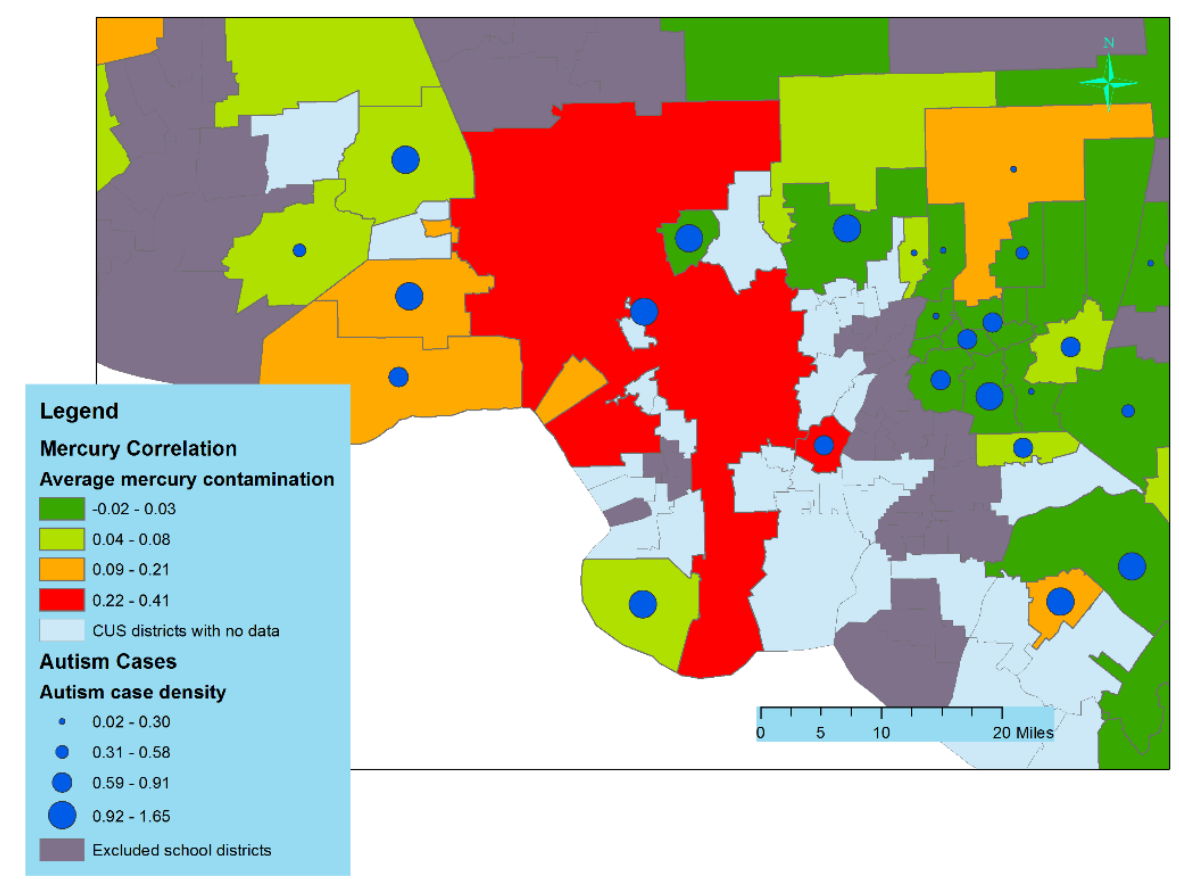

Figure 5-7: Close up image of analysis area

In the image above, focus is centered around the Los Angeles Unified School District to give a close up view of the analysis area. Further explanation of symbology will follow in the next chapter. 


\section{Chapter 6 - Results and Analysis}

Now that the implementation has been completed, conclusions can now be drawn from the presented data. This analysis will be broken down into three sections: an analysis of how mercury compares to the number of autism cases, then how lead compares, and finally how both mercury and lead compare against each other as well as with the total cases. Finally, a summary conclusion will be presented using all of the available data.

In the maps below, autism data will be displayed in the number of cases per 100 students. The mercury and lead data will be displayed in parts per million.

\subsection{Mercury and autism analysis}

First, an examination of a map with only the mercury data and autism data has been presented. What insight can be obtained from looking at it? Background literature suggests that mercury contamination can be a key factor in the development in autism.

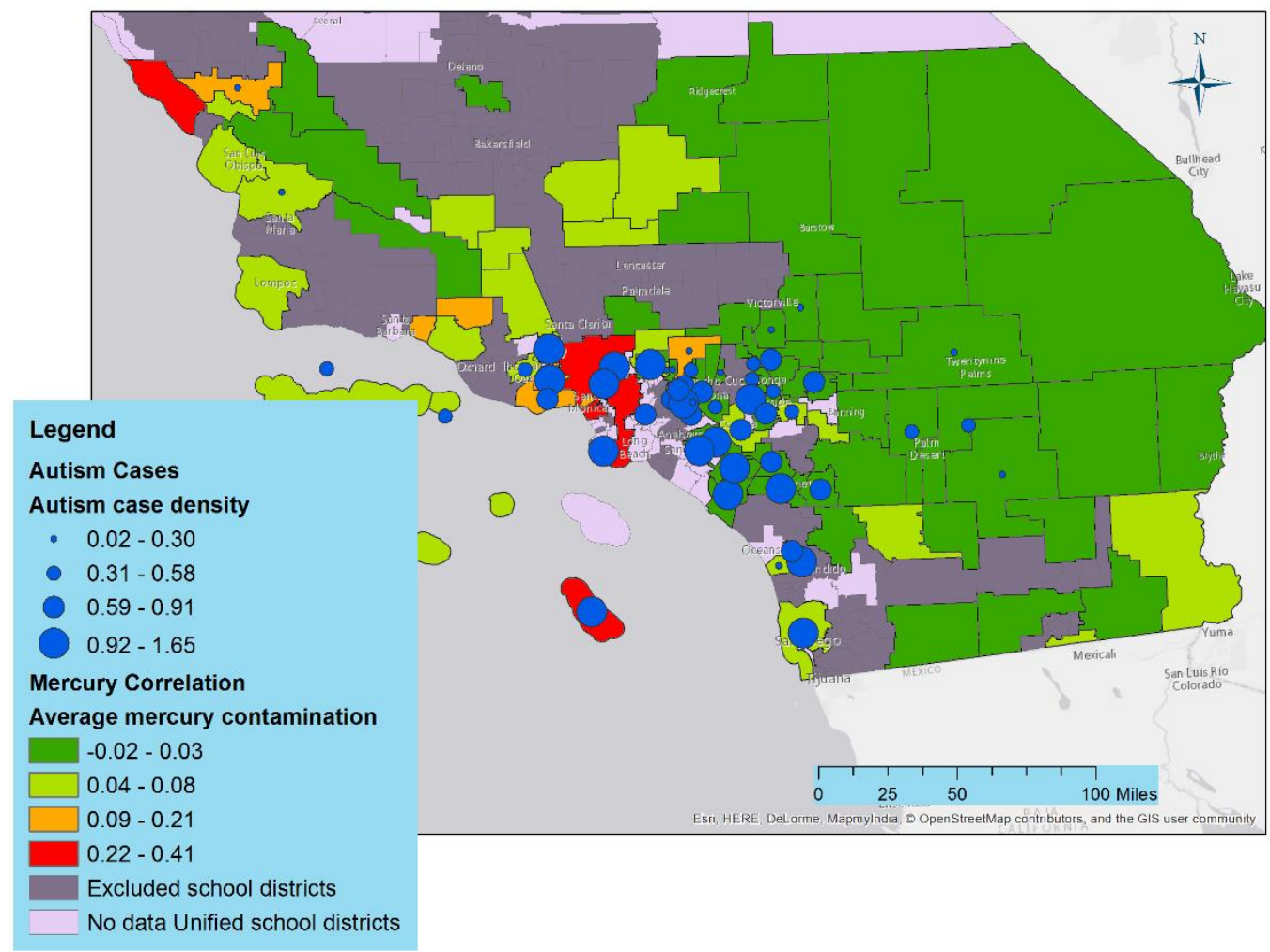

Figure 6-1: Mercury presence map

This first map is a small scale view of the California school districts. Districts not part of this analysis have been shaded out. Autism data is displayed in a per 100 students 
format while the mercury data is in a parts per million format. One of the first things that is noticeable is that mercury contamination is not as extensive as one would believe. In fact, with the data presented, extensive mercury presence can be found only in a few places. Both the Los Angeles unified school district and the Coast unified school district boast the highest mercury presence based on the data. However, there are a number of other districts that cannot be clearly seen in this map. Now, a closer look at our analysis area is necessary. In the following map, a close of up of the Los Angeles Unified school district and surrounding districts is used.

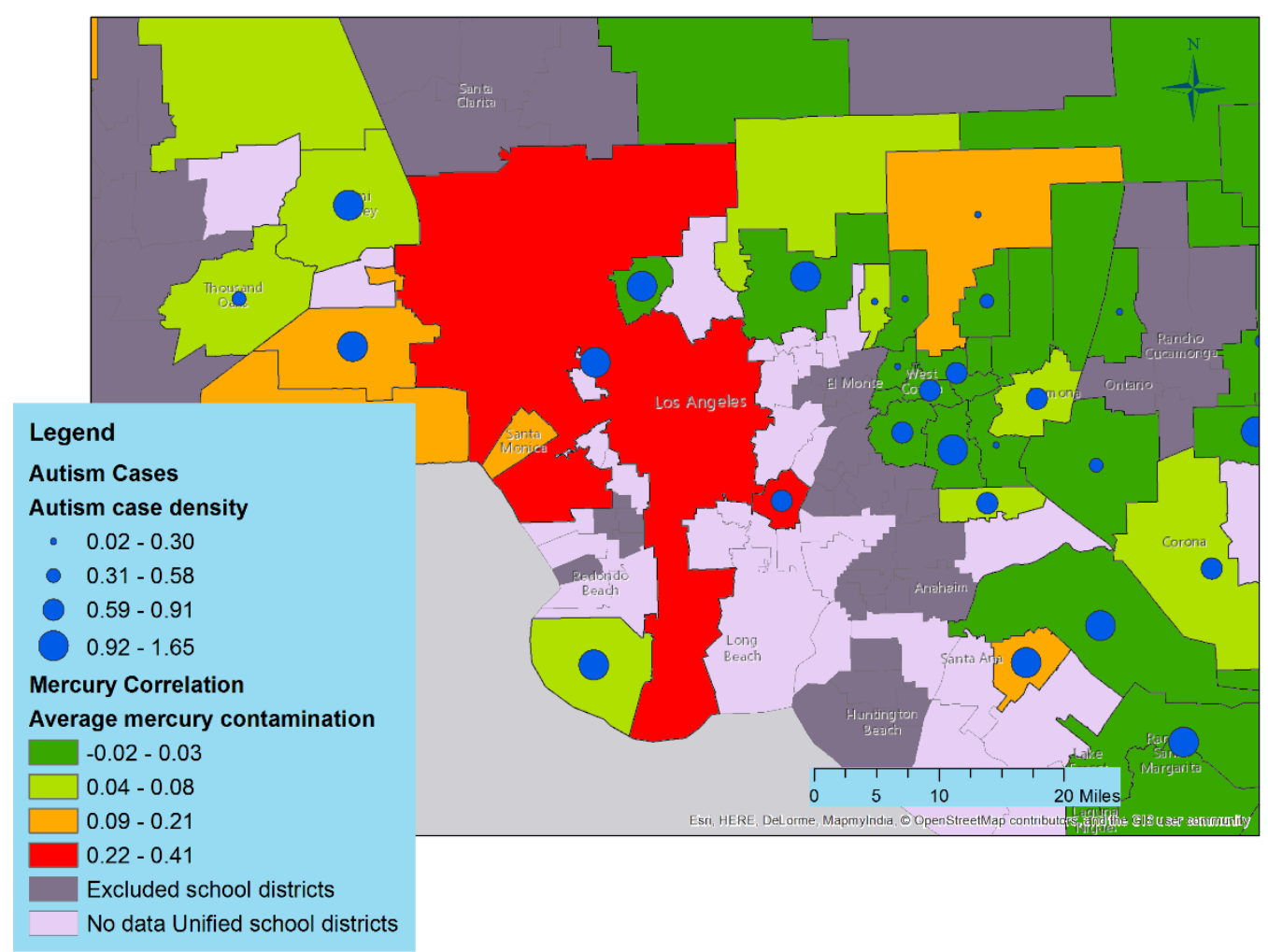

Figure 6-2: Close up view of mercury presence

From this map, one can also see that the Downey Unified School District located directly to the east of Los Angeles Unified also boasts of a very high mercury presence.

This can be due to a number of factors. Given that mercury is a highly transitory element and is found in both a number of commercial products as well as used in a great many industrial processes, one would expect to see greater mercury presences. However, since this data is limited only to data collected from the US geochemical survey, it is unlikely that it is a comprehensive image of total mercury presence.

In fact, the USGS makes explicit note that mercury is a difficult element to obtain samples for and that due to the ease of sample contamination, much of the data pertaining to mercury was obtained though reanalysis (Interior, 2012). However, how does this data look when compared to the autism data? From this map alone, not much can be told about the comparison between the two. For that, a graphical representation has been compiled to better examine this. 
In the below table, orange is used to represent the number of autism cases per 100 students and blue is used to represent the amount of mercury in parts per million.

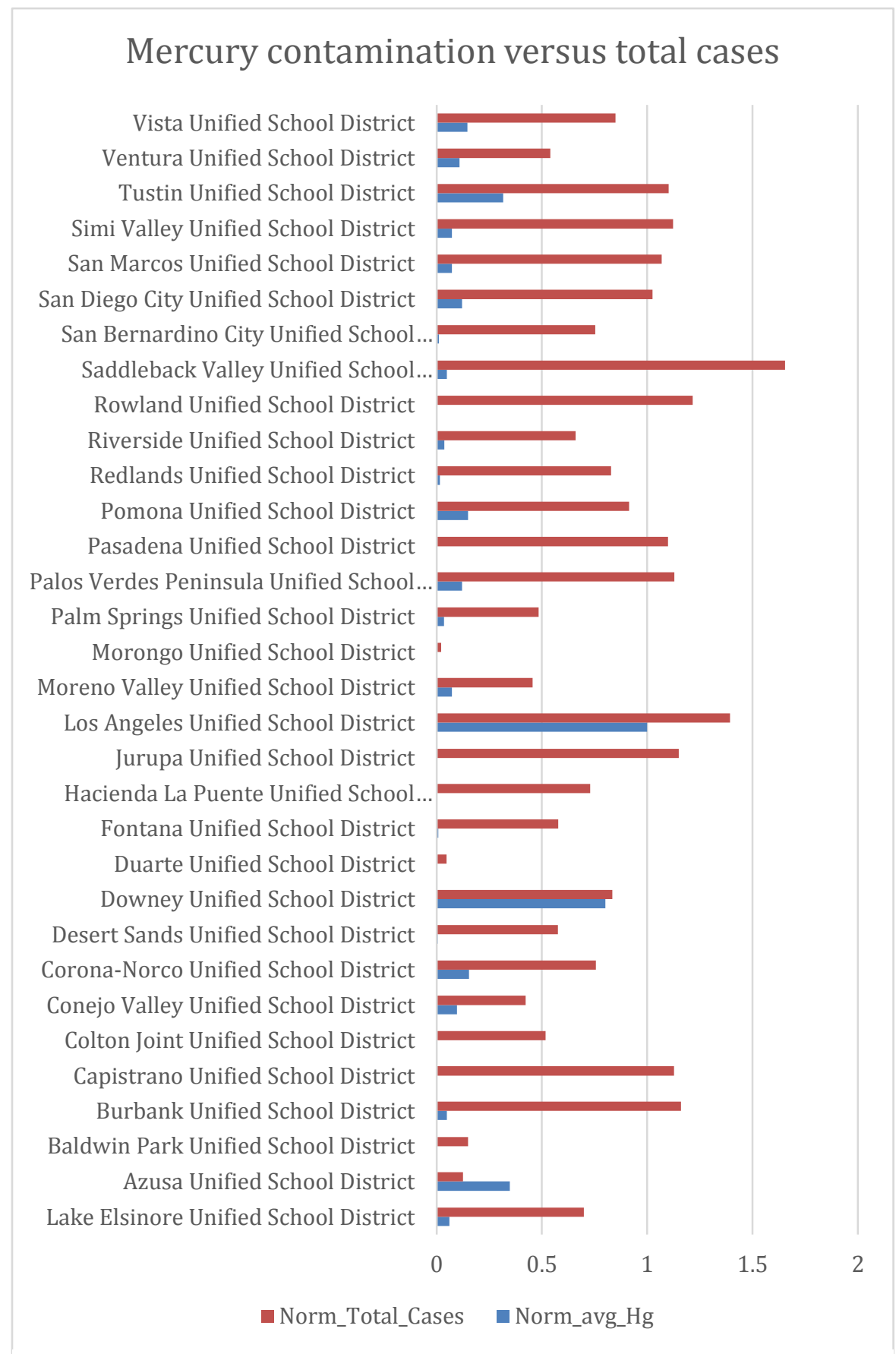

\section{Table 2: Autism/mercury relations in table format}

Immediately, one can tell that there is not nearly as much mercury contamination when compared to the number of autism cases. In fact, only in two school districts is the mercury contamination anywhere close to the number of autism cases. Azusa school district however is an anomaly for it has a higher part per million mercury presence than per 100 student case density. While the data shows that this district has less than ten 
thousand students, it also has autism presence from ages 2 to 11 with significant presence in the age 5 and age 6 brackets.

Based on the map data, one would also expect to see the Coast unified school district represented on this graph. Unfortunately, accurate autism numbers for that district were not available so it was omitted from this graph. Also from this chart, another anomaly can be detected. The Azusa Unified School District is the only district that has a higher mercury presence than presence of autism. A pearson correlation analysis between the collected mercury data and autism case data yielded a result of 0.2199 . This is a very weak correlation. That number suggests that with the data presented, there is not a strong correlation between autism cases and mercury present in the environment. Now, background literature suggests that there is a stronger correlation between this element and autism, but with the data used for this project, no such claim can be made.

\subsection{Lead and autism analysis}

From the presented data, mercury does not have a strong correlation with autism cases. But what about lead? Below, another graphical representation is presented with the focus being on the presence of lead as opposed to mercury.

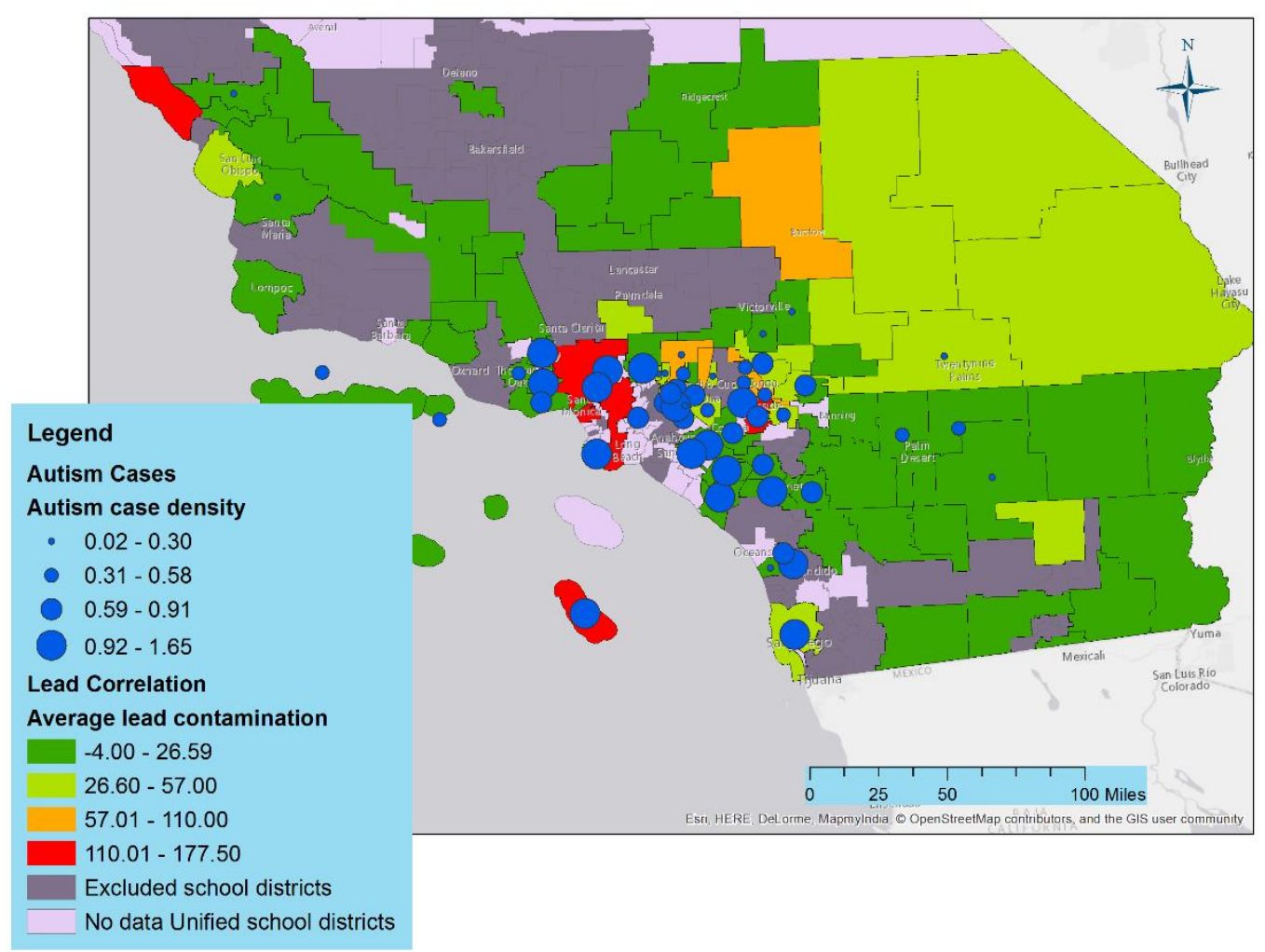

Figure 6-3: Lead presence map 
When compared to the mercury map, there does appear to be a higher presence of lead than mercury. This warrants a closer look.

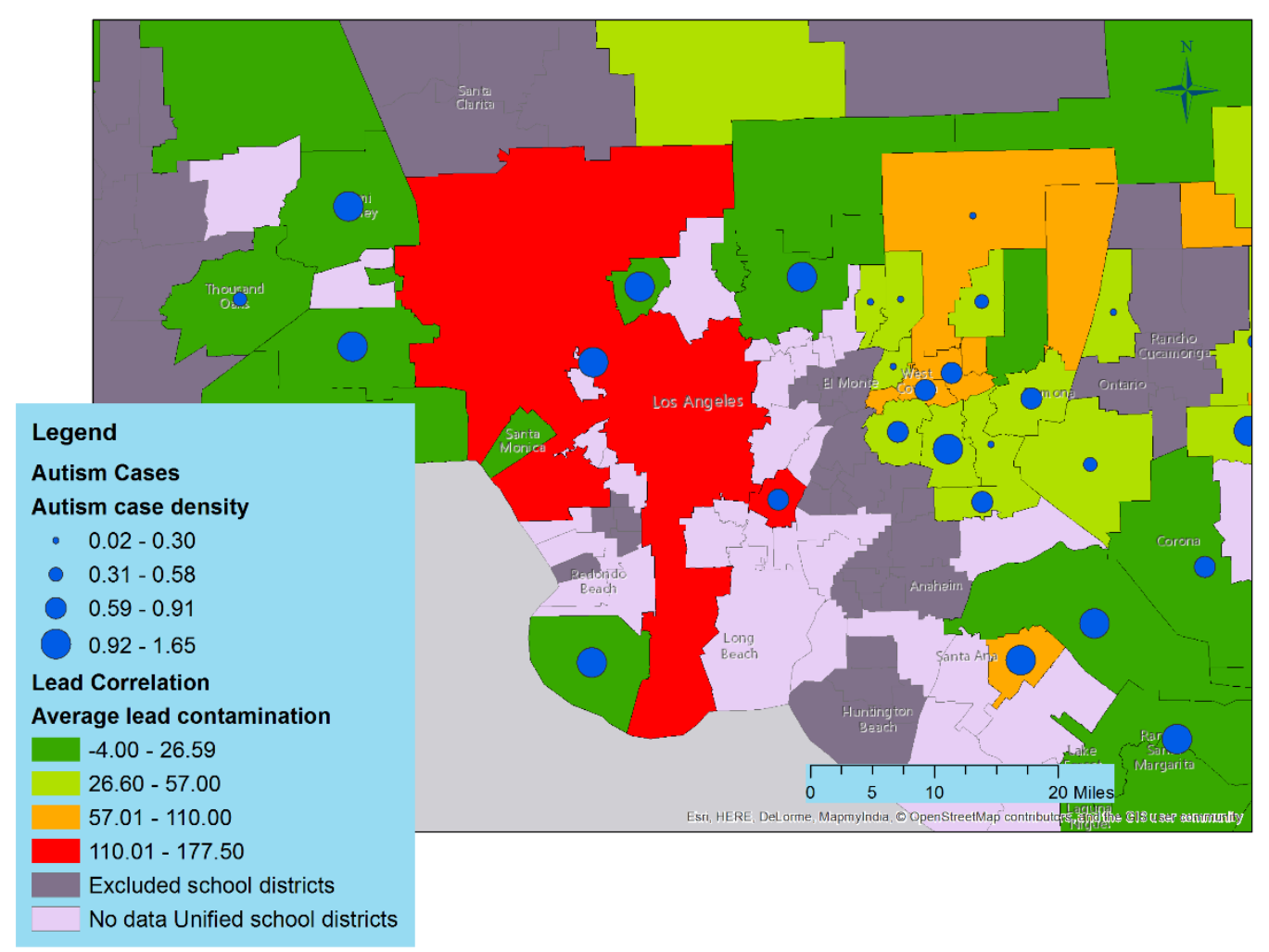

Figure 6-4: Close up view of lead presence

From the map, it would appear that the presence of lead is greater than that of mercury. In addition to the Los Angeles Unified School District, the Downey Unified school district and the Riverside Unified School District also show high lead presence. While the Los Angeles district continues to show a normalized autism rate of 1.4 students with autism per 100, Downey and Riverside are not far behind with rates of .83 students and .66 students per 100 respectively. 
Now when looking for this from a graphical standpoint, other things become clear. Again, autism data is normalized per 100 students and lead is in a parts per million format.

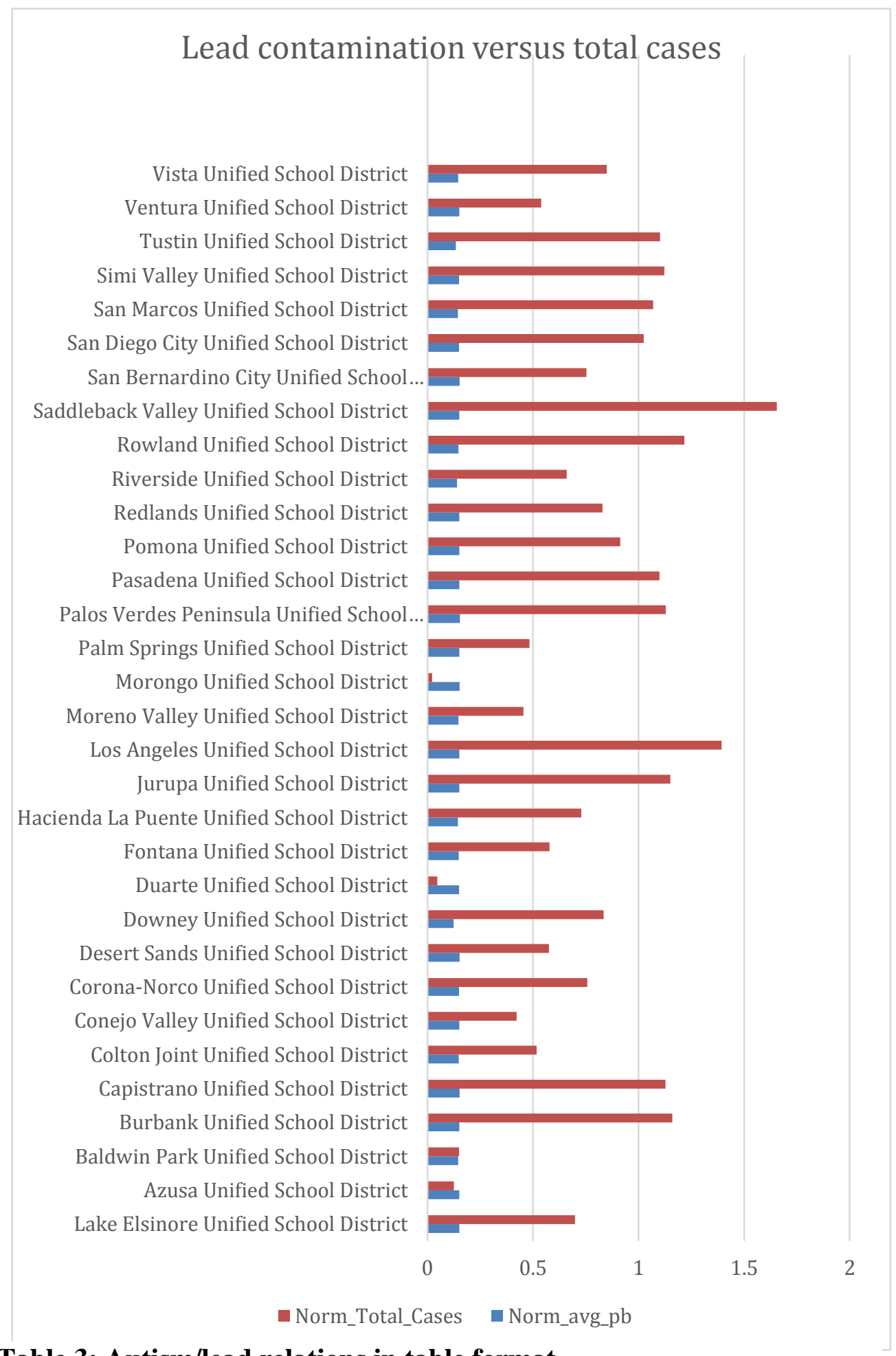

Table 3: Autism/lead relations in table format 
From this representation of the data, lead contamination appears to be much more consistent than mercury. This may be attributed to the fact that mercury, with is a liquid a room temperature and can easily be transferred as mentioned in Chapter 2. This can lead to it being more present in some areas while less present in others. While lead, which was used mostly as a component in other items as well as a byproduct of petroleum usage is much more widespread overall. In fact, after normalization the range between the minimum and maximum for lead was a variation of only .03 per 100 students while with mercury there was a range of over .8 per 100 students.

\subsection{Mercury and lead}

Now, in order to examine what it would look like if the mercury data and the lead data were on the same map, the autism data will be put aside. Will there be any correlation between where mercury is highest and where lead is most present?

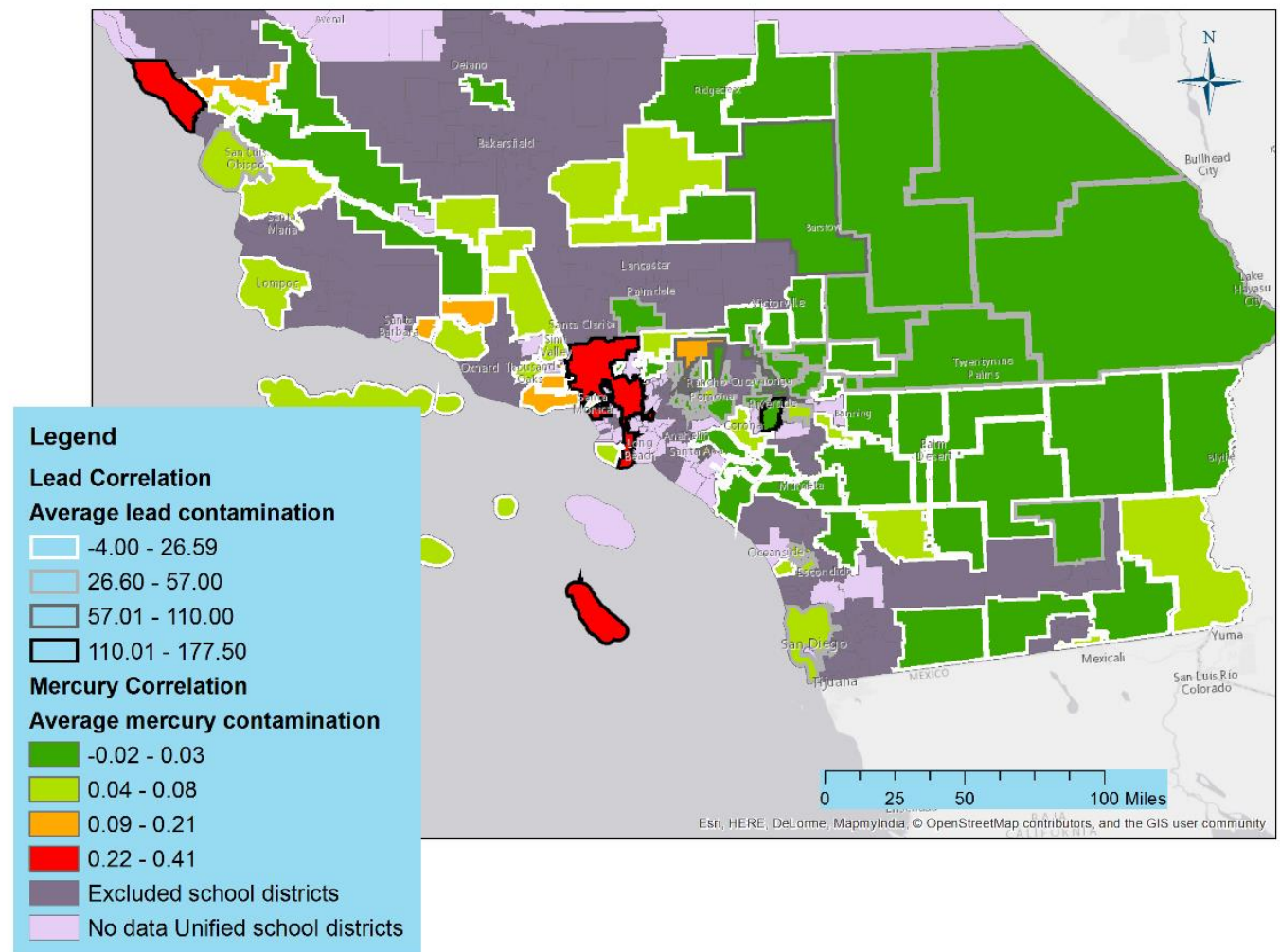

Figure 6-5: Mercury vs lead comparison map

In this map, the mercury data was retained in the above green to red format to denote presence. The lead data was shifted from that format to a white to black outline scale in order to more easily compare where both substances were strongest. It can be easily seen from this format that in the most urban areas, in this case the Los Angeles Unified School District and the Coast Unified School District in the upper left edge of the map. Here, the presence of both mercury and lead were highest. Other areas denote various presences of 
the two substances, but only in that area was there a strong presence of both contaminants.

\subsection{Summary}

From the data collect and used for this analysis, no strong correlations between either mercury and autism nor lead and autism can be made. That said, there was a stronger correlation between lead and autism than mercury with an inverse correlation of -0.03 while mercury itself has a value of 0.21 



\section{Chapter 7 - Conclusions and Future Work}

\subsection{Conclusion}

At the end of this project, it has become clear that the complexity of the autistic condition is very vast with a large number of penitential environmental contributors still unknown. The author's hypotheses stated that the presence of mercury and lead have a negative impact on the presence and severity of autism. While examined documentation does support this, analysis was not able to confirm that within the study area. This can mean that contamination was not of a high enough level to have an adverse effect on the human biology. It can also mean that the gathered data was not comprehensive enough to support the stated hypothesis. Also, aggregation of the autism data at the school district level prevented a detailed analysis. Additional work must be conducted to prove or disprove whether or not these and other contaminants have a notable impact on both autism prevalence and severity.

\subsection{Future Work}

For future work on this project, the inclusion of additional environmental contaminants should be included. This would allow for a greater understanding in regards to the presence of multiple contaminants has a cumulative effect where as individual elements only have a marginal effect. It would also be to the benefit of this project that the study area either be broadened if more comprehensive autism data can be attained that way or even narrowed to focus on a single school district level if individual case data can be found and used. 


\section{Chapter 8 - Works Cited}

Adams, J., Baral, M., Geis, E., Mitchell, J., Ingram, J., Hensley, A., . . El-Dahr, J. (2009). The Severity of Autism Is Associated with Toxic Metal Body Burden and Red Blood Cell Glutathione Levels. Journal of Toxicology. doi:10.1155

Aisha, S. D. (2015). Autism spectrum disorder prevalence and proximity to industrial facilities releasing arsenic, lead, or mercury. Science of the Total Environment(536), 245-251.

American Psychiatric Association. (2013). Autism Spectrum Disorder. In A. P. Association, Diagnostic and Statistical Manual of Mental Disorders, Firth Edition (pp. 51-59). Arlington, Virginia, United States of America: American Psychiatric Association.

Becerra, T. A., Wilhelm, M., Olsen, J., Cockburn, M., \& Ritz, B. (2013, March). Ambient Air Pollution and Autism in Los Angeles County, California. Environmental Health Perspectives, 121(3), 380-386.

Brown, T., McLafferty, S., \& Moon, G. W. (2010). A companion to Health and Medical Geography. Malden, MA: Wiley-Blackwell. Retrieved 05 16, 2016

Centers for Disease Control and Prevention. (2015, 8 12). Autism Spectrum Disorder: Data \& Statistics. Retrieved from Centers for Disease Control and Prevention: http://www.cdc.gov/ncbddd/autism/data.html

Ferrar, K. (2014, 9 15). California School District Enrollment Demographics with Well/Stimulation . Redlands, California, United States. Retrieved from http://univredlands.maps.arcgis.com/home/item.html?id=ded0e763c43f46d0b0ff4 227e5ef4b3f

Geier, D. A., King, P. G., \& Geier, M. (2008, October). A comprehensive review of mercury provoked autism. Indian Journal of Medical Research, 128(4), 383-411.

Ihde, E. S., Nyirenda, T., Jain, A. K., Loh, J. M., Artigas, F., Hobble, C., . . Rosen, L. (2014). Mapping Contaminants Associated with Autism: A Public Health Pilot in New Jersey. Journal of Geographic Information System, 706-722. Retrieved from http://dx.doi.org/10.4236/jgis.2014.66058

Interior, U. D. (2012, 3 14). Mineral resources On-Line Spatial Data. (J. Grossman, Producer) Retrieved 11 21, 2015, from USGS Geochemical Survey Database: http://mrdata.usgs.gov/geochem/doc/mercury.htm

Roberts, M, E., English, P. B., Grether, J. K., Windham, G. C., Somberg, L., \& Craig, W. (2007, October). Maternal Residence near Agricultural Pesticide Applications and Autism Spectrum Disorders. Environmental Healther Perspectives, 115(10), 1482-1489. Retrieved 10 13, 2014, from http://www.jstor.org/stable/4626943

US Department of Heath and Human Services. (2016, July 11). CDC Data and Statistics. Retrieved July 19, 2016, from Centers for Disease Control and Prevention: http://www.cdc.gov/ncbddd/autism/data.html

Volk, H. E., Hertz-Picciotto, I., Delwiche, L., Lurmann, F., \& McConnel, R. (2011, June). Residential Proximity to Freeways and Autism in the CHARGE Study. Environmental Health Perspectives, 119(6), 873-877. Retrieved 20 13, 2014, from http://www.jstor.org/stable/41203358 
Volk, H. E., Lurmann, F., Penfold, B., Hertz-Picciotto, I., \& McMonnell, R. (2013, Jan). Traffic-Related Air Pollution, Particulate Matter, and Autism. Jame Psychautry, 70(1), 71-77. 


